\title{
Methylphenidate for attention-deficit/hyperactivity disorder in adults: a narrative review
}

\author{
Rafał R. Jaeschke ${ }^{1}$ Ewelina Sujkowska ${ }^{2}$ Magdalena Sowa-Kućma ${ }^{2,3}$
}

Received: 10 February 2021 / Accepted: 31 July 2021 / Published online: 26 August 2021

(c) The Author(s) 2021

\begin{abstract}
Rationale Psychostimulants, including methylphenidate (MPH), are the mainstay of pharmacotherapy for attention-deficit/ hyperactivity disorder (ADHD) in adults. Even though MPH is the most commonly used medication for ADHD these days, there are relatively few resources available that provide comprehensive insight into the pharmacological and clinical features of the compound.

Objective The aim of this paper is to provide an up-to-date outline of the pharmacology and clinical utility of MPH for ADHD in adult patients.

Methods While conducting the narrative review, we applied structured search strategies covering the two major online databases (MEDLINE and Cochrane Central Register of Controlled Trials). In addition, we performed handsearching of reference lists of relevant papers.

Results Methylphenidate exhibits multimodal mechanism of action, working primarily as a dopamine and noradrenaline reuptake inhibitor. It also protects the dopaminergic system against the ongoing 'wearing off' (by securing a substantial reserve pool of the neurotransmitter, stored in the presynaptic vesicles). In placebo-controlled trials, MPH was shown to be moderately effective both against the core ADHD symptoms (standardized mean difference [SMD], 0.49; 95\% confidence interval [CI], 0.35-0.64), and the accompanying emotion regulation deficits (SMD, 0.34; 95\% CI, 0.23-0.45). The most common adverse events related to long-term treatment with MPH are decreased appetite $(\sim 20 \%)$, dry mouth (15\%), heart palpitations $(13 \%)$, gastrointestinal infections $(\sim 10 \%)$, and agitation/feeling restless $(\sim 10 \%)$.

Conclusions There is substantial body of evidence to suggest that MPH is an effective and safe treatment option for adults with ADHD.
\end{abstract}

Keywords Adult ADHD $\cdot$ Treatment $\cdot$ Psychostimulants $\cdot$ Methylphenidate $\cdot$ Pharmacology

Rafał R. Jaeschke

rafal.jaeschke@gmail.com

1 Section of Affective Disorders, Department of Psychiatry, Jagiellonian University Medical College, ul. Kopernika 21a, 31-501 Kraków, Poland

2 Department of Human Physiology, Institute of Medical Sciences, Medical College of Rzeszów University, ul. Kopisto 2a, 35-315 Rzeszów, Poland

3 Centre for Innovative Research in Medical and Natural Sciences, Medical College of Rzeszów University, ul. Warzywna 1a, 35-310 Rzeszów, Poland

\section{Introduction}

Attention-deficit/hyperactivity disorder (ADHD) is a common clinical condition, affecting around $1.5-5 \%$ of the population globally (Fayyad et al. 2017; Kooij et al. 2019a; Polanczyk et al. 2015). While often misperceived as 'a mental health problem of the youth', there is robust evidence to suggest that ADHD is actually a lifelong disorder, of neurodevelopmental origin (Breda et al. 2020; Demontis et al. 2019; Faraone et al. 2021), with the symptoms waxing and waning in contextual fashion (Asherson et al. 2016; Kooij et al. 2019a; Posner et al. 2020). Notably, the estimated point prevalence of ADHD among children and adolescents is quite similar to the corresponding data in adults (3-5\% and 1.4-3.6\%, respectively) (Fayyad et al. 2017; Polanczyk et al. 2015). Attention-deficit/hyperactivity disorder remains 
underdiagnosed and undertreated, in one part because of highly prevalent co-existence of other mental health problems (e.g., anxiety disorders, depression, bipolar disorder or personality issues [Katzman et al. 2017]); in other part due to the overlapping symptoms (notably, emotional dysregulation - making it hard to distinguish between ADHD and borderline personality disorder Beheshti et al. 2020; Moukhtarian et al. 2018).

While the formal diagnostic criteria for ADHD focus on the two major clusters of symptoms (inattention and hyperactivity/impulsivity) (American Psychiatric Association 2013; Reed et al. 2019; Volkow and Swanson 2013), this purely descriptive approach seems to be missing the point (Posner et al. 2020; Wong et al. 2019). From the clinical perspective, treatment for ADHD is primarily about patientimportant outcomes, rather than any pre-specified diagnostic measures. Given the trait-like nature of the condition (which is to say that 'the symptoms [of ADHD] do not reflect a change from the premorbid state' [Asherson et al. 2016; cited verbatim]), it is vital for a clinician to comprehend the specific areas of functional impairment - as experienced by the individual patient.

Notably, while the above-mentioned areas of disability are certainly related to the 'narrow' ADHD symptomatology (see Table 1), they are not mutually equivalent (Boland et al. 2020; Canadian ADHD Resource Alliance [CADDRA] (2018); Joseph et al. 2019; Kooij et al. 2019b). Even though the severity of the core symptoms of hyperactivity/impulsivity (and, to a lesser extent, inattention [Franke et al. 2018]) seems to decrease over time, no similar trend is observed in terms of corresponding impairment in daily functioning (Faraone et al. 2015, 2006). The tangential relationship between the overt ADHD symptomatology on the one hand, and the actual burden of the condition on the other is particularly puzzling, as it sets a specific (and apparently counterintuitive) frame of reference for clinical decision-making. Having said that, one might ask, what does it 'really' mean to have ADHD?

In order to address this question in a relevant manner, it is worth beginning with the emphasis on what ADHD is not. Accordingly, the clinical condition discussed in this paper is not actually about (as self-evident as seemingly disjoined) a set of difficulties related to sustaining attention and 'having hard time sitting still', or - at the very least - that is just the tip of the iceberg. In fact, there is plenty of data to suggest that the core clinical phenomenon related to ADHD (and the major source of the condition-specific impairment) is the excessive spontaneous mind wandering (MW) (Bozhilova et al. 2018; Christoff et al. 2016). One should also bear in mind that another significant driver behind the ADHD-related impairments are emotion regulation deficits (observed in about $34-70 \%$ of adults with ADHD) (Hirsch et al. 2018, 2019).
From the point of view of the MW hypothesis, what tends to be seen 'from the outside' as mere attention deficits should be perceived as a by-product of unrestrained variability of thought movement, which - in turn - reflects the diminished ability to 'suppress internally oriented cognition' (Christoff et al. 2016; cited verbatim). In plain words, individuals with ADHD are distracted primarily by their own train of thoughts, ever less relevant to the task at hand. Mind wandering typical for ADHD can be, thus, seen as a reflection of insufficient cognitive control mechanisms, overstretched by environmental demands (relentlessly changing in their quality and quantity [Vatansever et al. 2019]). However, this is not the end of the story, as there are some specific features of the ADHD-related MW, making it different from 'ordinary daydreaming': the ineffectiveness of context regulation (i.e., the frequency of wandering thoughts is not constrained easily, regardless of the situation), perceptual decoupling (i.e., reduced capacity to respond to external sensory stimuli when 'roaming mentally'), and a clear sense of relief while engaging in salient and rewarding activities (Bozhilova et al. 2018). Mind wandering has been found to be closely related to all the three dimensions of ADHD symptomatology (i.e., attention deficits, hyperactivity, and impulsivity) - as well as the corresponding emotional dysregulation. At the same time, the intensity of MW seems to be independent from the history of traumatic brain injuries, substance use disorders, educational deficits, or perinatal adverse outcomes - further substantiating the idea that the phenomenon of spontaneous MW is the specific, (dys)functional hub of ADHD (Biederman et al. 2019).

The MW hypothesis is particularly important from the clinical perspective, because it makes is easier to see ADHDrelated challenges for what they really are. Actually, the experience of ADHD can be compared to the predicament of a chess player immersing oneself in endless analyses, while finding it very hard to make any 'real-life' decisions regarding the moves on the board - and ultimately losing on time. Notably, the MW perspective also provides some important insights into the pathogenesis of the condition. Not only is mind wandering the key predictor of the level of impairment related to ADHD (Biederman et al. 2019; Bozhilova et al. 2018; Helfer et al. 2019), it also seems to be a direct consequence of some specific neural disruptions. As described in the seminal paper by Bozhilova et al. (2018), 'the MW hypothesis proposes that altered interaction between the four large scale networks (default mode network [DMN], executive control network, salience network and visual network), and that deficient DMN deactivation during task activities will lead to excessive spontaneous MW, lacking in coherence and topic stability, which in turn will lead to ADHD symptomatology' (cited verbatim). Overall, ADHD is nowadays considered to be primarily a 'brain connectivity disorder' (Demontis et al. 2019; Michelini et al. 2019; Sudre 
Table 1 Symptomatology of attention-deficit/hyperactivity disorder and the corresponding areas of functional impairment

\begin{tabular}{|c|c|}
\hline \multicolumn{2}{|l|}{ The symptoms } \\
\hline Inattention & $\begin{array}{l}\text { - Failing to pay close attention to details and making careless mistakes at work or other activi- } \\
\text { ties } \\
\text { - Difficulty sustaining attention } \\
\text { - Seemingly 'not listening' when spoken to directly } \\
\text { - Often failing to follow through on given instructions and finding it hard to finish chores or } \\
\text { duties in the workplace } \\
\text { - Having problems organizing tasks and activities } \\
\text { - Being reluctant to engage in tasks that require sustained mental effort } \\
\text { - Often losing things that are necessary for given tasks or activities } \\
\text { - Being easily distracted by irrelevant stimuli or unrelated thoughts ('wandering mind') } \\
\text { - Often being forgetful in daily activities }\end{array}$ \\
\hline Hyperactivity and impulsivity & $\begin{array}{l}\text { - Often fidgeting with or tapping hands or feet / squirming in one's seat } \\
\text { - Often leaving one's seat in situations in which one is expected to remain seated } \\
\text { - Often feeling restless (or agitated inside; finding it hard to relax) } \\
\text { - Finding it hard to engage in leisure activities quietly } \\
\text { - Often 'being on the go'; acting as if 'driven by a motor' } \\
\text { - Talking excessively } \\
\text { - Often blurting out answers before a question has been completed } \\
\text { - Often finding it difficult (frustrating) while awaiting one's turn (e.g., waiting in line) } \\
\text { - Often interrupting or intruding on others }\end{array}$ \\
\hline \multicolumn{2}{|l|}{ The likely areas of impairment (with examples) } \\
\hline Health problems and psychiatric comorbidities & $\begin{array}{l}\text { - Specific learning disorders and executive dysfunctions } \\
\text { - Developmental coordination disorders } \\
\text { - Speech and language disorders } \\
\text { - Mood and anxiety disorders } \\
\text { - Autism spectrum disorders } \\
\text { - Obsessive-compulsive disorder } \\
\text { - Tic disorder } \\
\text { - Substance use disorders } \\
\text { - Overweight, obesity and related metabolic disorders } \\
\text { - Accidents (including driving safety issues) and related injuries } \\
\text { - Suicidality }\end{array}$ \\
\hline Other reasons for functional impairment & $\begin{array}{l}\text { - Undermined sense of well-being (i.e., lower quality of life) } \\
\text { - Emotional dysregulation:* } \\
\text { - Problems with temper control (i.e., pronounced irritability with frequent, yet short-lived, } \\
\text { outbursts of anger) } \\
\text { - Emotional over-reactivity (i.e., noticeable problems with managing 'everyday stressors', } \\
\text { leading to the pervasive sense of being overwhelmed) } \\
\text { - Mood lability (i.e., typically swinging from normal mood, to sadness, to mild excitement - } \\
\text { and back again...) }\end{array}$ \\
\hline Academic and occupational challenges & $\begin{array}{l}\text { - Under-performing at school or at work } \\
\text { - 'Staying back' (e.g., repeating classes), as a consequence of problems related to inattention } \\
\text { - Special education needs } \\
\text { - School expulsion / dropping out }\end{array}$ \\
\hline Social/interpersonal problems & $\begin{array}{l}\text { - Inadequate social skills } \\
\text { - Long-term pattern of impaired family / intimate relationships }\end{array}$ \\
\hline
\end{tabular}

\footnotetext{
* Reduced ability to modulate the current emotional state in a contextually adequate and goal-directed manner
}

Adapted from American Psychiatric Association (2013), Volkow and Swanson (2013), Shaw et al. (2014), Faraone et al. (2015), Moukhtarian et al. (2018), Kooij et al. (2019b) and Boedhoe et al. (2020)

et al. 2018); the evidence on the structural correlates of the condition is less certain (for details, see a series of reports from neuroimaging studies by the ENIGMA-ADHD Working Group: Boedhoe et al. [2020]; Hoogman et al. [2017], [ 2019] and Zhang-James et al. [2021]).

Psychostimulants (methylphenidate [MPH], dexamphetamine, and lisdexamphetamine) are the mainstay of pharmacotherapy for ADHD in adults (Bolea-Alamañac et al. 2014a, b). Even though MPH is the most commonly used medication for ADHD these days (Raman et al. 2018), there are relatively few resources available that provide comprehensive insight into the pharmacological and clinical features of the compound. Therefore, the aim of this paper is to deliver a concise overview of the current knowledge on 
the utility of MPH in the population of adults diagnosed with ADHD.

\section{Methods}

While it is not a formal systematic review, we applied structured search strategies covering the two major online databases (PubMed / MEDLINE and Cochrane Central Register of Controlled Trials; for the MeSH terms, see Table 2). In order to confine the findings to the reliable clinical data (thus applying the idea of 'new evidence pyramid' [Murad et al. 2016]), we focused primarily on high-quality systematic reviews (Murad et al. 2014) and treatment guidelines (Brouwers et al. 2010; Shekelle 2018). Following the recent methodological advice by Faltinsen et al. (Faltinsen et al. 2019), we considered observational studies as potentially valuable addition to randomized controlled trials (RCTs) on ADHD in adults.

Bearing in mind that the notion of hierarchy of medical evidence applies primarily to clinical practice, we applied more inclusive criteria while searching for pharmacological studies (Table 2). In addition, we performed handsearching of reference lists from articles identified in the online databases.

\section{Methylphenidate: chemistry and general pharmacology}

First synthesized in 1944, the compound nowadays known as MPH belongs to the class of phenylethylamines and is chemically identified as methyl-2-phenyl-2-(piperidin-2-yl) acetate. The molecular formula of MPH is $\mathrm{C}_{14} \mathrm{H}_{19} \mathrm{NO}_{2}$ and its mass equals $233.31 \mathrm{~g} / \mathrm{mol}$ (Lange et al. 2010; Wenthur 2016). There are four configurational isomers of MPH, with the $d$-threo enantiomer being the most active pharmacologically (Dinis-Oliveira 2017; Markowitz et al. 2003a). The earliest formulations of MPH (as approved by the U.S. Food and Drug Administration [FDA]) were rapidly released and absorbed into the bloodstream, and then metabolized just as quickly. Significant progress in the techniques of drug formulation (especially over the previous two decades) resulted in the launch of new pharmaceutical preparations including various enantiomers of MPH, with distinct pharmacokinetic profiles (including extended-release formulations), or dosage forms (Childress et al. 2019; Markowitz et al. 2003a). It was a watershed moment in the history of treatments for ADHD, since the availability of a wide range of MPH formulations enables for 'tailoring' of the treatment regimens to the individual needs of the patients (notably, this aspect seems to be particularly relevant for adults [Kooij 2013]).

Methylphenidate was identified as a psychostimulant already in 1954, but to this day, the mechanism by which it exerts behavioral effect has not been fully elucidated. However, it is assumed that antagonism against the dopamine (DA) and noradrenaline (NA) transporters (DAT and NAT, respectively) plays the pivotal role (Cortese 2020; Lange et al. 2010).

\section{An overview of the specific formulations of methylphenidate}

Due to the fact that an MPH molecule contains two chiral carbon atoms in its structure, it can exist as four isomers, which are usually divided into two pairs of enantiomers: erythro [ $d-\left(2 \mathrm{R}: 2^{\prime} \mathrm{R}\right)$ and $\left.l-\left(2 \mathrm{~S}: 2^{\prime} \mathrm{S}\right)\right)$ and threo [ $d$ - (2R:2'R) and $l$ - (2S:2'S)) (see Fig. 1). The early formulations introduced in the market in the 1950s included a mixture of both racemates $(80 \%(d / l)$-erythro and $20 \%(d / l)$-threo) (Bartl et al. 2017; Heal and Pierce 2006; Markowitz et al. 2003a). As it became clear that the central stimulating effects of methylphenidate are associated with the activity of threo isomers administration, while erythro isomers cause some adverse side effects, the production of more purified preparations became the subject of interest (Childress et al. 2019; Markowitz et al. 2003a). Therefore, subsequent generations of the drug contained only the threo enantiomers in equal proportions between the $d-\left(2 \mathrm{R}: 2^{\prime} \mathrm{R}\right)$ and $l-(2 \mathrm{~S}: 2$ 'S $)$ forms of the molecule (which is the case for the majority of the

Table 2 Search strategy

\begin{tabular}{ll}
\hline PubMed/MEDLINE & Cochrane Central Register of Controlled Trials \\
\hline For clinical data: & "methylphenidate hydrochloride" in Title Abstract Keyword AND \\
(("Methylphenidate"[Mesh]) AND "Attention Deficit Disorder with & "ADHD" in Title Abstract Keyword AND adult* in Title Abstract \\
Hyperactivity"[Mesh]) AND "Adult"[Mesh] & Keyword-with Cochrane Library publication date Between Jan \\
For pharmacological data: & 2018 and Sep 2020 (Word variations were searched) \\
( "Methylphenidate/metabolism"[Mesh] OR "Methylpheni- & \\
date/organization and administration"[Mesh] OR "Methyl- & \\
phenidate/pharmacokinetics"[Mesh] OR "Methylphenidate/ & \\
pharmacology"[Mesh] OR "Methylphenidate/physiology"[Mesh] & \\
OR "Methylphenidate/poisoning"[Mesh] OR "Methylphenidate/ & \\
toxicity"[Mesh]) &
\end{tabular}


currently available formulations). Finally, high-purity formulations containing $d$-threo-MPH only (the most potent form of the drug) were developed. The drug containing only this isomer is sometimes called $d$-TMP, although other names, dexmethylphenidate, D-MPH, or D-threomethylphenidate, are used more commonly in the literature (DinisOliveira 2017; Markowitz et al. 2003a) Fig.2.

The history of clinical use of MPH started with the immediate-release (IR) formulations. However, due to their rapid metabolism, and thus the need to apply them multiple times a day, many patients find the treatment regimen not very comfortable (Childress et al. 2019; Kooij 2013; Maldonado 2013; Markowitz et al. 2003a; Patrick et al. 2019; Swanson et al. 1999, 2003). As a response to this challenge, the sustained-release (SR) and - later on - extended-release (ER) formulations were developed (Markowitz et al. 2003a). Nowadays, the mainstay of treatment for ADHD are the 'long-acting/dual release' MPH capsules, combining IR and ER formulations in varying proportions (IR $20-50 \%$ and ER 50-80\%; see Table 3). This ingenious resolution ensures both the rapid onset of action and durability of the clinical effects (for details, see Childress et al. 2019 and Kooij 2013).

In addition to the 'classical' oral tablets and capsules, chewable tablets are also available. The extensive product range is complemented by oral solutions or suspensions and transdermal patch (Cortese et al. 2017; Wenthur 2016) (for details, see Table 3). The wide variety of available formulations, using various drug delivery systems (e.g., osmoticrelease oral system MPH: OROS MPH; methylphenidate transdermal system: MTS, and MPH extended-release oral suspension: MEROS), as well as diverse composition (in terms of the proportions of both the $d / l$ enantiomers and the content of the IR:ER formulations within the tablet/capsule), contribute to the better acceptability of the treatment (as compared to the 'simple' IR formulations of MPH) (Childress et al. 2019; Wenthur 2016).

\section{Pharmacokinetic profile of methylphenidate}

Regardless of the type of formulation, the active component of the medication is the highly soluble salt: MPH hydrochloride (Childress et al. 2019).

Following oral administration, MPH absorbs quickly and almost completely from the gastrointestinal tract and buccal mucosa (Patrick et al. 2005). Low pH inhibits the non-enzymatic hydrolysis of MPH; hence, the gastric juice probably only slightly decomposes it. However, due to a large first-pass effect, the absolute bioavailability (F) is low

Table 3 An overview of the available formulations of methylphenidate

\begin{tabular}{|c|c|c|}
\hline Brand name & Formulation and dosage form & Doses available \\
\hline Adhansia XR® & Methylphenidate hydrochloride; extended-release capsules & $25,35,45,55,70,85 \mathrm{mg}$ \\
\hline Aptensio XR ${ }^{\mathrm{TM}}$ & Methylphenidate hydrochloride; extended-release capsules & $10,15,20,30,40,50,60 \mathrm{mg}$ \\
\hline Concerta ${ }^{\circledR}$ & Methylphenidate hydrochloride; extended-release tablets & $18,27,36,54 \mathrm{mg}$ \\
\hline Cotempla XR-ODT ${ }^{\mathrm{TM}}$ & Methylphenidate extended-release orally disintegrating tablets & $8.6,17.3,25.9 \mathrm{mg}$ \\
\hline Daytrana ${ }^{\circledR}$ & Methylphenidate transdermal patch & $\begin{array}{l}10 \mathrm{mg} / 9 \mathrm{~h}(1.1 \mathrm{mg} / \mathrm{h}) \\
15 \mathrm{mg} / 9 \mathrm{~h}(1.6 \mathrm{mg} / \mathrm{h}) \\
20 \mathrm{mg} / 9 \mathrm{~h}(2.2 \mathrm{mg} / \mathrm{h}) \\
30 \mathrm{mg} / 9 \mathrm{~h}(3.3 \mathrm{mg} / \mathrm{h})\end{array}$ \\
\hline Focalin $^{\mathrm{TM}}$ & Dexmethylphenidate hydrochloride; immediate-release tablets & $2.5,5,10 \mathrm{mg}$ \\
\hline Focalin $\mathrm{XR}^{\mathrm{TM}}$ & Dexmethylphenidate hydrochloride; extended-release capsules & $5,10,15,20,25,30,35,40 \mathrm{mg}$ \\
\hline Jornay $\mathrm{PM} ®$ & Methylphenidate hydrochloride; extended-release capsules & $20,40,60,80,100 \mathrm{mg}$ \\
\hline Metadate $\mathrm{CD} ®$ & Methylphenidate hydrochloride; extended-release capsules & $10,20,30,40,50,60 \mathrm{mg}$ \\
\hline Methylin® & Methylphenidate hydrochloride; immediate-release oral solution & $5 \mathrm{mg} / 5 \mathrm{ml}, 10 \mathrm{mg} / 5 \mathrm{ml}$ \\
\hline Methylin ER® & Methylphenidate hydrochloride; extended-release chewable tablets & $10,20 \mathrm{mg}$ \\
\hline Quillichew ER ${ }^{\circledR}$ & Methylphenidate hydrochloride; extended-release chewable tablets & $20,30,40 \mathrm{mg}$ \\
\hline Quillichew XR ${ }^{\circledR}$ & Methylphenidate hydrochloride; extended-release oral suspension & $5 \mathrm{mg} / \mathrm{ml}$ \\
\hline Ritalin $®$ & Methylphenidate hydrochloride) immediate-release tablets & $5,10,20 \mathrm{mg}$ \\
\hline Ritalin LA® & Methylphenidate hydrochloride) extended-release capsules & $10,20,30,40 \mathrm{mg}$ \\
\hline
\end{tabular}

Additional remarks:

1. This overview covers the FDA-approved (and currently available) medications, containing methylphenidate as the active ingredient, including available strengths, formulation and dosage form. Most of them are for oral use (except Daytrana ${ }^{\circledR}$ - transdermal patches) and contain a mixture of $d / l$ enantiomers (except Focalin $\mathrm{XR}^{\mathrm{TM}}-d$-MPH)

2. Numerous generics under the name methylphenidate hydrochloride and dexmethylphenidate hydrochloride were omitted from the list

ER/XR extended release, FDA U.S. Food and Drug Administration, LA long-acting, MPH methylphenidate

Adapted from Childress et al. (2019) and FDA (Food and Drug Administration 2004, 2010a, b, 2017a, b, c, d, 2019) 
and in humans oscillates between 0.11 and 0.53 , while in monkeys and rats, the corresponding values equal are to 0.22 and 0.19, respectively (Chan et al. 1983; Kimko et al. 1999; Markowitz et al. 2003a; Wargin et al. 1983; Wenthur 2016). The peak plasma concentration $\left(\mathrm{C}_{\max }\right)$ depends primarily on the type of formulation and shows high interindividual variability (see Table 4).

In the case of the IR formulations, there is consistent research data to suggest that time to reach $\mathrm{C}_{\max }\left(\mathrm{T}_{\max }\right)$ ranges from 1 to $3 \mathrm{~h}$, and the onset of action is already observable about $20 \mathrm{~min}$ after the ingestion of the drug (Spiller et al. 2013). On the other hand, the corresponding evidence pertaining to the ER formulations of MPH is much more heterogeneous (which reflects significant differences in terms of the specific release systems, as designed and used by individual manufacturers) (Cortese et al. 2017). For example, after oral administration of OROS MPH, the plasma concentrations of the drug increase rapidly, reaching an initial maximum at $\sim 1 \mathrm{~h}$, followed by gradual ascending concentrations over the next 5 to $9 \mathrm{~h}$. Then, a gradual decrease in concentration is observed. Regardless of the dose, $\mathrm{T}_{\max }$ for OROS MPH oscillates between 6 and $10 \mathrm{~h}$ (McNeil Pediatrics 2007), while $\mathrm{T}_{1 / 2}$ is about 2.6-3 $\mathrm{h}$ (Leonard et al. 2004). When taken during a meal, MPH reaches the $\mathrm{C}_{\max }$ about $1 \mathrm{~h}$ later (Spiller et al. 2013) (see Table 4). It was also reported that the fat content in the meal may either accelerate or slow down the absorption of MPH, with no major impact on other pharmacokinetic parameters (Chan et al. 1983; Markowitz et al. 2003a; Modi et al. 2000b). The effects of fat-rich meals on the $\mathrm{C}_{\max }$ value may differ substantially (of note, this remark applies primarily to some ER formulations). Both combined IR/ER and OROS MPH formulations are characterized by lower absorption ratio, while the liquid-based ER MPH exhibits elevated levels of $\mathrm{C}_{\max }$, when ingested with fatty meals (Food and Drug Administration 2017b; 2018).

Methylphenidate is highly soluble in lipids and shows low (15\%) plasma protein binding; therefore, it is rapidly distributed to various tissues (in rats: kidney $>$ lungs $>$ brain $>$ heart $>$ liver) (Dinis-Oliveira 2017; Kimko et al. 1999; Patrick et al. 2005; Volkow et al. 1995; Wolraich and Doffing 2004). The concentration of the drug measured in the brain was shown to be approximately eight times higher than the corresponding value detected in the blood, regardless of the route of administration (intravenous vs. oral) (Patrick et al. 2005). A positron emission tomography (PET) study in humans showed that $7.5 \%( \pm 1.5 \%)$ of $\left[{ }^{11} \mathrm{C}\right]-\mathrm{MPH}$ molecules (administered intravenously) enter the brain, with the highest concentration detected in the striatum, and significantly lower in the cortex and cerebellum (Food and Drug Administration 2017b; Volkow et al. 1995). In a subsequent study performed by the same team of researchers, it was found that various MPH isomers
( $l$ - and $d$-threo) are distributed differently within the brain (Ding et al. 1997). Accordingly, the maximum regional uptake of $\left[{ }^{11} \mathrm{C}\right]-d$-threo-MPH was detected in the basal ganglia, while the uptake ratio of $\left[{ }^{11} \mathrm{C}\right]-l$-threo-MPH was similar across the brain. The volume of distribution ratio for the basal ganglia to cerebellum (DVB/DVC) at the steady-state was ranging between 2.2 and 3.3 for $\left[{ }^{11} \mathrm{C}\right]-d$-threo-MPH in baboons and humans, and was equal to 1.1 for $\left[{ }^{11} \mathrm{C}\right]-l$-threo-MPH (Ding et al. 1997). In baboons, pretreatment with unlabeled MPH led to significant decrease of $\left[{ }^{11} \mathrm{C}\right]-d$-threo-MPH uptake in the striatum, but not in the cerebellum. At the same time, no changes in DVB/DVC ratio after $\left[{ }^{11} \mathrm{C}\right]-l$-threo-MPH administration were observed (Ding et al. 1995). Also, a microdialysis study in rats indicated markedly increased extracellular dopamine levels (by about 650\%) after $d$-threo-MPH administration (which was not the case for $l$-threo-MPH) (Ding et al. 1997).

The above-mentioned findings suggest that pharmacological specificity of MPH resides entirely on the $d$-threo isomer. They also indicate that binding of the $l$-isomer in the human brain is mostly nonspecific.

Methylphenidate undergoes fast systemic clearance (as calculated by Markowitz et al. 2003b, the oral clearance ratio is approximately $4.5 \mathrm{~L} / \mathrm{kg} / \mathrm{h}$ ), with little or no accumulation of the drug 'from day to day' - regardless of the formulation used (Modi et al. 2000a, 2000c; Rochdi et al. 2004). That is why, treatment with MPH keeps on following an 'on-off mode' (with typical late afternoon rebounds of ADHD symptoms [Kooij 2013]), rather than reaching a stable 'plateau' (pharmacokinetic or clinical) (Patrick et al. 2005). At the same time, it needs to be emphasized that the fast systemic clearance of MPH is coupled (somewhat paradoxically) with the slow clearance from the brain (Volkow et al. 1995).

In general terms, there are no major differences in the pharmacokinetic parameters of MPH between children, adolescents, and adults (Cortese et al. 2017; Markowitz et al. 2003a; Wenthur 2016). On the other hand, there is some variation in these parameters between men and women. For example, Patrick et al. (2007) observed a lower bioavailability of MPH in blood of women $(n=10)$ with a simultaneously stronger stimulating effect compared to the group of men $(n=10)$. Interestingly, brain studies found consistently higher concentrations of MPH in female rats than in males, which contributed to a consistently higher exposure of the brain to the drug. The observed gender differences may be a consequence of the different metabolic rate of the drug. There was a significant decrease in the clearance of MPH in the brain of females as compared to males, especially in the case of the $d$-enantiomer (Bentley et al. 2015). Other factors, such as the rate of drug transport across the blood-brain barrier, genetic and hormonal factors, or the influence of 
Table 4 Pharmacokinetic properties of some of the FDA-approved formulations of MPH in healthy adults (except for Daytrana ®; see the footnote)

\begin{tabular}{|c|c|c|c|c|c|c|c|c|c|}
\hline \multirow[t]{3}{*}{ Brand name } & \multirow[t]{3}{*}{ Dose tested } & \multirow[t]{3}{*}{ Dosage } & \multirow[t]{3}{*}{ Food } & \multirow[t]{3}{*}{ PK profile } & \multicolumn{4}{|l|}{ PK parameters } & \multirow[t]{3}{*}{ References } \\
\hline & & & & & $\begin{array}{l}\mathrm{AUC}_{0 \text {-inf }}(\mathrm{ng} / \\
\left.\mathrm{ml}^{*} \mathrm{~h}^{-1}\right)\end{array}$ & $\mathrm{T}_{\max }(\mathrm{h})$ & $\mathrm{C}_{\max }(\mathrm{ng} / \mathrm{ml})$ & $\mathrm{T}_{1 / 2}(\mathrm{~h})$ & \\
\hline & & & & & \multicolumn{4}{|c|}{ Mean \pm SD or median (min. - max.) } & \\
\hline $\begin{array}{c}\text { Adhansia } \\
\text { XR }{ }^{\circledR}\end{array}$ & $100 \mathrm{mg}$ & $\begin{array}{l}\text { Multiple } \\
\text { (once } \\
\text { daily for } \\
5 \text { days) }\end{array}$ & Fasting & 2 peaks & $\begin{array}{l}\mathrm{AUC}_{0-24:} \\
227.17 \pm 83.61\end{array}$ & $\begin{array}{l}\mathrm{T}_{\max 1:} \\
1.5(1-2.5) \\
\mathrm{T}_{\max 2:} \sim 12 \\
(8.5-16.0)\end{array}$ & $15.73 \pm 4.54$ & $\sim 7$ & $\begin{array}{l}\text { Food and } \\
\text { Drug } \\
\text { Admin- } \\
\text { istration } \\
2019\end{array}$ \\
\hline Concerta ${ }^{\circledR}$ & $18 \mathrm{mg}$ & Single & & 1 peak & $41.8 \pm 13.9$ & $6.8 \pm 1.8$ & $3.7 \pm 1.0$ & $3.5 \pm 0.4$ & $\begin{array}{l}\text { Food and } \\
\text { Drug } \\
\text { Admin- } \\
\text { istration } \\
\text { 2017a }\end{array}$ \\
\hline $\begin{array}{l}\text { Cotempla } \\
\text { XR-ODT } \\
\text { TM }\end{array}$ & $51.8 \mathrm{mg}$ & Single & & 1 peak & $169.1 \pm 57.13$ & $\begin{array}{l}4.98(2.5- \\
6.5)\end{array}$ & $20.8 \pm 5.22$ & $4.0 \pm 0.73$ & $\begin{array}{l}\text { Food and } \\
\text { Drug } \\
\text { Admin- } \\
\text { istration } \\
2017 b\end{array}$ \\
\hline $\begin{array}{l}\text { Daytrana } \\
\text { ® } 1\end{array}$ & $\begin{array}{c}12.5 \mathrm{~cm}^{2} / 9 \mathrm{~h} \\
(10 \mathrm{mg} / 9 \mathrm{~h})\end{array}$ & Single & & 1 peak & $48.7 \pm 21.9$ & $\begin{array}{l}10.0(6.00- \\
12.0)\end{array}$ & $4.15 \pm 2.59$ & $4.35 \pm 0.788$ & $\begin{array}{l}\text { Childress } \\
\text { et al. } \\
2019 ; \\
\text { Food and } \\
\text { Drug } \\
\text { Admin- } \\
\text { istration } \\
2017 \mathrm{c}\end{array}$ \\
\hline $\begin{array}{l}\text { Focalin } \\
\mathrm{XR}^{\mathrm{TM}^{2}}\end{array}$ & $20 \mathrm{mg}$ & Single & & 2 peaks & $119.1 \pm 40.7$ & $\begin{array}{l}\mathrm{T}_{\max 1:} 1.5(1- \\
2.0) \\
\mathrm{T}_{\max 2:} 6.5(4.5 \\
-7.0)\end{array}$ & $\begin{array}{l}\mathrm{C}_{\max 1:} \\
13.7 \pm 4.6 \\
\mathrm{C}_{\max 2:} \\
14.9 \pm 4.0\end{array}$ & $3.26 \pm 0.51$ & $\begin{array}{l}\text { Food and } \\
\text { Drug } \\
\text { Admin- } \\
\text { istration } \\
2004\end{array}$ \\
\hline$\underset{\circledR}{\text { Ritalin LA }}$ & $20 \mathrm{mg}$ & Single & & 2 peaks & $45.8 \pm 10.0$ & $\begin{array}{l}\mathrm{T}_{\max 1:} \\
2.0 \pm 0.9 \\
\mathrm{~T}_{\max 2:} \\
\quad 5.5 \pm 0.8\end{array}$ & $\begin{array}{l}\mathrm{C}_{\max 1:} 5.3 \pm 0.9 \\
\mathrm{C}_{\max 2:} 6.2 \pm 1.6\end{array}$ & $3.3 \pm 0.4$ & $\begin{array}{l}\text { Food and } \\
\text { Drug } \\
\text { Admin- } \\
\text { istration } \\
\text { 2010b }\end{array}$ \\
\hline Methylin ${ }^{\circledR}$ & $2 \mathrm{mg} / \mathrm{ml}$ & Single & $\begin{array}{l}\text { Fasting } \\
\text { Satiety }\end{array}$ & 1 peak & $\begin{array}{l}51.91 \pm 24.73 \\
64.95 \pm 25.21\end{array}$ & $\begin{array}{l}1.707 \pm 0.444 \\
2.667 \pm 0.747\end{array}$ & $\begin{array}{l}9.391 \pm 3.002 \\
10.693 \pm 2.639\end{array}$ & $\begin{array}{l}2.955 \pm 0.602 \\
2.897 \pm 0.663\end{array}$ & $\begin{array}{l}\text { Food and } \\
\text { Drug } \\
\text { Admin- } \\
\text { istration } \\
\text { 2010a }\end{array}$ \\
\hline $\begin{array}{c}\text { Methylin } \\
\text { ER } ®\end{array}$ & $20 \mathrm{mg}$ & Single & $\begin{array}{l}\text { Fasting } \\
\text { Satiety }\end{array}$ & 1 peak & $\begin{array}{l}41.19 \pm 7.71 \\
51.12 \pm 9.69\end{array}$ & $\begin{array}{l}4.17 \pm 0.95 \\
4.38 \pm 1.09\end{array}$ & $\begin{array}{l}4.59 \pm 0.79 \\
6.64 \pm 1.19\end{array}$ & $\begin{array}{l}4.38 \pm 1.30 \\
3.21 \pm 1.00\end{array}$ & $\begin{array}{l}\text { Food and } \\
\text { Drug } \\
\text { Admin- } \\
\text { istration } \\
\text { 2017d }\end{array}$ \\
\hline
\end{tabular}

${ }^{1}$ Daytrana ${ }^{\circledR}$ - results drawn from a study on ADHD in adolescents

${ }^{2}$ Focalin XR TM is the only product containing solely $d$-MPH; the other formulations are the mixtures of $d / l-\mathrm{MPH}$

$P K$ profile/parameters pharmacokinetic profile/parameters, $A D H D$ attention-deficit/hyperactivity disorder, $A U C_{0-i n f}$ area under the concentration - time curve to infinite time, $C_{\max }$ peak plasma concentration after drug administration, ER/XR extended-release, FDA U.S. Food and Drug Administration, $M P H$ methylphenidate, $S D$ standard deviation, $T_{\max }$ time to reach $\mathrm{C}_{\max }, T_{1 / 2}$ half-life

the immune system, may also play a role. Unfortunately, the role of these putative mechanisms has so far been poorly understood and requires further research (Kok et al. 2020).
Methylphenidate is metabolized in the liver, mainly by endoplasmic reticulum human carboxylesterase $1 \mathrm{~A} 1$ (CES1A1) through a de-esterification process into the 
inactive metabolite phenyl-2-piperidine acetic acid, also known as (either $d$ - or $l$-threo) ritalinic acid (Childress et al. 2019). The process described here is enantio-selective, which implies significantly higher plasma concentration and longer $\mathrm{T}_{1 / 2}$ of $d$-MPH in comparison to $l$-MPH (because CES1A1 has six-fold higher preference for $l$-MPH versus $d$-MPH) (Dinis-Oliveira 2017). Notably, CES1A1 is closely related to CES2; however, MPH is metabolized by CES1 only (Stevens et al. 2019). In studies on various oral formulations of MPH, it was shown that $\mathrm{AUC}_{0 \text {-inf }}$ for the $l$ enantiomer is equal to just $1-15 \%$ of the $\mathrm{AUC}_{0 \text {-inf }}$ value for $d-\mathrm{MPH}$ (Patrick et al. 2005). Despite the fact that $l$-MPH has a lower bioavailability, it is likely that this enantiomer is more stable in human plasma than $d$-MPH, while less stable in human erythrocytes (Ramos et al. 1999; Srinivas et al. 1991). The rule of enantio-selectiveness also applies to the trans-esterification of MPH, which occurs after co-administration of MPH with ethanol (Markowitz et al. 2000, 1999). There are some preliminary reports suggesting that the product of the trans-esterification (known as ethylphenidate - EPH) may actually be toxic (Dinis-Oliveira 2017).

In addition, hydroxylated metabolites of MPH have also been detected in a number of preclinical studies (involving various animal species). Of note, some of the compounds (e.g., para-hydroxy-MPH) exhibit pharmacological activity in mice (effect not studied in humans), even greater than that of MPH (Wenthur 2016). Para-hydroxy-MPH undergoes further de-esterification and glucuronidation and gives the final inactive product: $p$-hydroxy-ritalinic acid glucuronide.

As a consequence of microsomal oxidation, 6-oxo-methylphenidate (another inactive metabolite of MPH) may be formed, which is further converted to 6-oxo-ritalinic acid via de-esterification (Stevens et al. 2019).

Methylphenidate is eliminated as ritalinic acid (approximately $60-80 \%$ of a dose taken), predominantly with urine. After oral administration, $50 \%$ of a dose of methylphenidate is excreted in the urine within $8 \mathrm{~h}$ and $90 \%$ by $48 \mathrm{~h}$ postadministration (Wolraich and Doffing 2004). About 1-3\% of the dose administered orally is excreted in feces, and less than $1-2 \%$ is eliminated unchanged in urine (Childress et al. 2019; Stevens et al. 2019).

\section{Drug-drug interactions}

Only a few clinically significant pharmacokinetic interactions involving MPH have been identified so far (Childress et al. 2019; Schoretsanitis et al. 2019).

Since the kinetics of MPH release is pH-dependent (this remark refers mostly to the XR formulations), a co-administration with gastric acid modulators may alter its release, $\mathrm{pK}$ profile, and pharmacodynamics. Hence, a simultaneous use of proton pump inhibitors (e.g., omeprazole, esomeprazole, pantoprazole) or $\mathrm{H}_{2}$-blockers (e.g., famotidine) or antacids (e.g., sodium bicarbonate) is not recommended (Food and Drug Administration 2017b, 2019). Also, the mechanisms of active drug release from individual formulations can also be severely altered by concomitant alcohol consumption. It was reported that most of the long-acting formulations show a much faster release of the active ingredient when co-administered with beverages containing $\geq 40 \%$ of alcohol (Childress et al. 2019). The interaction of ethanol with $d / l$ or $d$-MPH increased the $\mathrm{C}_{\max }$ by $22 \%$ and $15 \%$, respectively, and was linked to stronger stimulating effects of MPH (Zhu et al. 2017).

Due to the fact that $d / l-\mathrm{MPH}$ does not significantly inhibit any of the cytochrome P450 enzymes (1A2, 2C8, $2 \mathrm{C} 9,2 \mathrm{C} 19,2 \mathrm{D} 6,2 \mathrm{E} 1$ and $3 \mathrm{~A}$ isoforms), the metabolism of other xenobiotics and the detoxification processes are not particularly disturbed during its intake. For example, the co-administration of MPH and desipramine (a CYP2D6 substrate) did not increase the plasma level of this antidepressant. As mentioned above, MPH is hydrolyzed mostly by the CES1A1 enzyme. Therefore, MPH should be cautiously used in patients who are simultaneously treated with some strong CES1A1 inhibitors. Specifically speaking, the four drugs (aripiprazole, perphenazine, thioridazine, fluoxetine) have relatively high affinity to the above-mentioned enzyme (with the half maximal inhibitory concentration $\left[\mathrm{IC}_{50}\right]$ values of $5.7 \mu \mathrm{M}, 13.9 \mu \mathrm{M}, 7.0 \mu \mathrm{M}, 6.1 \mu \mathrm{M}$, respectively), which results in a significant increase in the plasma concentration of MPH (if co-prescribed) (Dinis-Oliveira 2017; Zhu et al. 2010).

To some extent, the metabolism of MPH may be also inhibited by alcohol. Ethanol is known to diminish the activity of CES1A1, while enhancing the transesterification process. As a result, EPH is formed, the presence of which is associated with an increased concentration of $d$-MPH in the blood plasma and increased euphoric effect in humans (Childress et al. 2019).

According to Schoretsanitis et al. (the authors of a recent systematic review [Schoretsanitis et al. 2019]), polytherapy with MPH and strong inducers of drug metabolizing enzymes (with carbamazepine as the prime example; but the interactions between MPH and phenobarbital, phenytoin or rifampin cannot be excluded either) may lead to significant decrease in the blood concentration of MPH. On the other hand, co-administration of imipramine might lead to increase of the bioavailability of MPH. Therefore, the authors concluded that MPH should not be prescribed simultaneously with the above-mentioned medications.

\section{Pharmacodynamics}

The pharmacological activity of MPH results primarily from its direct inhibition of the dopamine and noradrenaline transporters (DAT and NAT, respectively), which is due 
to its partial similarity of the basic structure to catecholamines. In vitro studies suggest that MPH is characterized by particularly high affinity (independent of the model used) for DAT (solute carrier family 6A member 3 - SLC6A3), slightly lower to NAT (solute carrier family 6A member 2 - SLC6A2), with virtually no effect on the activity of the serotonin transporter (SERT; also known as solute carrier family 6A member 4 - SLC6A4) (Markowitz et al. 2006; Markowitz and Patrick 2008; Williard et al. 2007). It was reported that MPH has almost 1300 times greater affinity for NAT, and about 2200 times greater affinity for DAT, in comparison to SERT (Stevens et al. 2019). Noteworthy, there is considerable variation in the strength of MPH binding to both DAT and NAT, depending on the enantiomer used (Markowitz and Patrick 2008). Accordingly, $d$-MPH was found to exert the highest affinity (DAT: $\mathrm{IC}_{50}=23 \mathrm{nM}$, $\mathrm{K}_{\mathrm{i}}=161 \mathrm{nM}$; NAT: $\left.39 \mathrm{nM}, \mathrm{K}_{\mathrm{i}}=206 \mathrm{nM}\right), d / l$-MPH mixture exhibited the intermediate binding potency (DAT: $\mathrm{IC}_{50}=20 \mathrm{nM}, \mathrm{K}_{\mathrm{i}}=121 \mathrm{nM}$; NAT: $51 \mathrm{nM}, \mathrm{K}_{\mathrm{i}}=788 \mathrm{nM}$ ), and the $l$-enantiomer had the least effect on the activity of the transporters (DAT: $\mathrm{IC}_{50}=1600 \mathrm{nM}, \mathrm{K}_{\mathrm{i}}=2250 \mathrm{nM}$; NAT: $\mathrm{IC}_{50}>10^{4} \mathrm{nM}, \mathrm{K}_{\mathrm{i}}>10^{4} \mathrm{nM}$ ) (Riddle et al. 2007; Sandoval et al. 2002; Williard et al. 2007) (for a review, see also Markowitz and Patrick 2008).

Methylphenidate was shown to affect the redistribution of vesicular monoamine transporter-2 (VMAT-2; solute carrier family 18 member 2 - SLC18A2), which is involved in the sequestration of cytoplasmic dopamine and noradrenaline, and thus is an important regulator of neurotransmission. Two studies showed that administration of MPH caused a decrease in VMAT-2 immunoreactivity in the membraneassociated fraction, an increase in the cytoplasmic fraction, and no change in the total synaptosomal pool. These results confirm that MPH does not affect the global amount of VMAT-2 in presynaptic terminals, but only its trafficking (Riddle et al. 2007; Sandoval et al. 2002). The maximum effect of MPH was observed $1 \mathrm{~h}$ after administration and returned to control values after $2 \mathrm{~h}$. Notably, the MPHinduced redistribution of VMAT-2 was observed only in monoaminergic neurons (as opposed to either cholinergic, GABA-ergic or glutamatergic cells) (Riddle et al. 2007).

Taken together, MPH increases the availability of DA (by inhibiting the DAT), while protecting the dopaminergic system against the ongoing 'wearing off' (by securing a substantial reserve pool of the neurotransmitter, stored in the presynaptic vesicles) (Fleckenstein et al. 2009; German et al. 2015). Those features are highly relevant from the clinical point of view, as they seem to translate into the relatively low risk of neurotoxic (or neuropsychiatric, in broader sense) side effects in patients treated with MPH (Fleckenstein et al. 2009; Krinzinger et al. 2019).

The overall outcome of the mechanisms described above is the boost of dopaminergic transmission in the brain, by extending the residence time (and activity) of impulsereleased DA in the synaptic cleft (see Fig. 2). Studies on the effects of MPH as a DAT blocker are quite hard to conduct, because of the heterogeneity of dopaminergic receptors. Although MPH has not been shown to have any affinity for dopamine receptors, it is likely to influence their function as well (Stevens et al. 2019). It is suggested that inhibition of dopamine reuptake by MPH reduces dopaminergic activity through increased stimulation of presynaptic inhibitory autoreceptors. Methylphenidate appears to bind to DAT (which blocks the access to the impulse-released catecholamine), but lacks the intrinsic activity necessary to induce the conformational change required for the transporter's shift (translocation) into the cytoplasm. Therefore, MPH does not influence the cytoplasmic transporter-facilitated release of dopamine into the synaptic cleft when the DAT reverts to its previous conformation (Patrick et al. 2019). Elevated dopamine levels following the MPH intake result in increased availability of the neurotransmitter, and its binding to both dopamine transporters and receptors (Faraone 2018). As suggested by some positron emission tomography (PET) studies, MPH in therapeutic doses blocks more than $50 \%$ of DAT and significantly increases the levels of extracellular DA in the basal ganglia, and this effect is modulated by the rate of DA release. In a sample of unmedicated patients with ADHD, an elevated binding of radiolabeled DA analogues in the striatum was reported (a finding suggestive for increased density of DAT molecules, as well). On the other hand, treatment with MPH reduced the number of the available DAT binding sites, and this was correlated with the alleviation of ADHD symptoms. In addition, some variability between DA inhibition and extracellular dopamine levels was observed, suggesting that MPH enhances the basal activity of the dopaminergic system (which remains in line with the hypothesis linking ADHD to diminished responsiveness of dopaminergic neurocircuitry) (Markowitz and Patrick 2008). Actually, administration of MPH leads to a three- to fourfold increase of both DA and NA (in the striatum, as well as the prefrontal cortex) (Hodgkins et al. 2012). By increasing dopaminergic activity in the brain, MPH elevates the overall activity of the central nervous system, with a number of significant behavioral and cognitive effects (for a review, see the article by Kapur 2020).

In a number of magnetic resonance imaging (MRI) studies, it was found that long-term administration of psychostimulants (including MPH) may reduce structural and functional abnormalities observed in the brains of individuals with ADHD (Costa et al. 2013; Frodl and Skokauskas 2012; Hart et al. 2013; Moeller et al. 2014; Mueller et al. 2014; Schlösser et al. 2009; Schweitzer et al. 2004; Spencer et al. 2013; Tomasi et al. 2011) (for a review, see the paper by Faraone 2018). 
Although most research on the pharmacological effects of MPH in ADHD is focused on the dopaminergic system, there is a growing body of evidence pointing to the significance of the noradrenergic component as well. Not only has MPH a relatively high affinity for NAT, but it also directly interacts with noradrenergic receptors (Andrews and Lavin 2006; Besnard et al. 2012; Furini et al. 2017; Gamo et al. 2010; Huang et al. 2018). Accordingly, it was reported that MPH binds to several subtypes of $\alpha$-adrenergic receptors: $\alpha_{2 \mathrm{~A}}\left(\mathrm{~K}_{\mathrm{i}}=5.6 \mu \mathrm{M}\right), \alpha_{2 \mathrm{~B}}\left(\mathrm{~K}_{\mathrm{i}}=2.420 \mu \mathrm{M}\right)$, and $\alpha_{2 \mathrm{C}}$ $\left(K_{i}=0.860 \mu \mathrm{M}\right)$ (Wenthur 2016). The procognitive effects of MPH (as related to the stimulation of the cerebral cortex) are hypothesized to be mediated by the interactions with the above-mentioned receptors (Andrews and Lavin 2006; Furini et al. 2017; Gamo et al. 2010).

It is not clear whether MPH has affinity for any serotonin receptors. Although the first study showed that both the $d$ and $l$ enantiomers have some binding potential for both $5-\mathrm{HT}_{1 \mathrm{~A}}$ and $5-\mathrm{HT}_{2 \mathrm{~B}}$; however, the next one only confirmed significant activity of $d$-MPH on $5-\mathrm{HT}_{1 \mathrm{~A}}$, but not $5-\mathrm{HT}_{1 \mathrm{~B}}$ receptors (Markowitz et al. 2006, 2009). Confusingly enough, another study on the potential affinity of MPH (in concentrations $<10 \mu \mathrm{M}$ ) towards either 5-HT or cholinergic receptors returned negative results (Besnard et al. 2012).

\section{Clinical considerations}

\section{Issues of efficacy and effectiveness}

The most comprehensive overview of the efficacy of MPH in adults to date has been provided in the systematic review with network meta-analysis by Cortese et al. (2018). Having synthesized the data collected from participants of 51 RCTs (overall, 8131 patients), the authors of this formidable piece of scientific work came up with a hierarchy of pharmacological treatments for ADHD. Accordingly, in terms of the impact on the core ADHD symptomatology, MPH was found to be significantly more effective than placebo, with the value of effect size remaining within the moderate range (as implied by the standardized mean difference of about 0.5 [Murad et al. 2014]). In comparison to active treatments, MPH turned out to be marginally-tomoderately less efficacious than amphetamines (including lisdexamphetamine), while exhibiting similar efficacy to atomoxetine and bupropion. Finally, modafinil was inferior to MPH. At the same time, the risk of leaving the study because of treatment-related adverse events was comparable across the groups (see Table 5).

Table 5 Efficacy and tolerability of MPH over the period of 12 weeks, as compared to placebo or other drugs used for ADHD in adults (adapted from Cortese et al. [2018])

\begin{tabular}{llllll}
\hline Comparator agent & Efficacy data & & \multicolumn{2}{l}{ Tolerability data } \\
\cline { 2 - 3 } \cline { 5 - 6 } & SMD $(95 \%$ CI $)$ & Certainty of evidence* & & OR (95\% CI) & Certainty of evidence* \\
\hline Amphetamines & -0.29 (from -0.54 to -0.05$)$ & $\oplus \oplus \bigcirc \bigcirc$ & $1.36(0.54-3.43)$ & $\oplus \bigcirc \bigcirc \bigcirc$ \\
Atomoxetine & 0.04 (from -0.14 to 0.23$)$ & $\oplus \oplus \oplus \bigcirc$ & $0.97(0.47-2.02)$ & $\oplus \oplus \bigcirc \bigcirc$ \\
Bupropion & $0.04($ from -0.38 to 0.45$)$ & $\oplus \oplus \bigcirc \bigcirc$ & $1.07(0.13-8.92)$ & $\oplus \bigcirc \bigcirc \bigcirc$ \\
Modafinil & $0.65(0.19-1.11)$ & $\oplus \oplus \bigcirc \bigcirc$ & $0.60(0.19-1.92)$ & $\oplus \bigcirc \bigcirc \bigcirc$ \\
Clonidine & No data available & & No data available & No data available \\
Guanfacine & No data available & & $2.39(1.40-4.08)$ & $\oplus \oplus \oplus \oplus$ \\
Placebo & $0.49(0.35-0.64)$ & $\oplus \oplus \oplus \bigcirc$ & &
\end{tabular}

The primary outcomes for efficacy and tolerability were, respectively, the clinician-rated severity of ADHD core symptoms and the proportion of participants who left the study due to any adverse event. Results in bold are statistically significant

The respective SMD cut-off scores of 0.2, 0.5, and 0.8 denote small, moderate, and large clinical effects (Murad et al. 2014)

$\mathrm{SMD}>0$ favours MPH; OR $>0$ favours comparator

* GRADE Working Group grades of evidence (cited verbatim from Balshem et al. [2011]):

High certainty $(\oplus \oplus \oplus \oplus)$ : We are very confident that the true value of outcome importance lies close to that of the estimate

Moderate certainty $(\oplus \oplus \oplus \bigcirc)$ : We are moderately confident in the estimate: the true value of outcome importance is likely to be close to the estimate, but there is a possibility that it is substantially different

Low certainty $(\oplus \oplus \bigcirc \bigcirc)$ : Our confidence in the estimate is limited: the true value of outcome importance may be substantially different from the estimate

Very low certainty $(\oplus \bigcirc \bigcirc \bigcirc)$ : We have very little confidence in the estimate: the true value of outcome importance is likely to be substantially different from the estimate

$C I$ confidence interval, GRADE Grading of Recommendations Assessment, Development and Evaluation, $M P H$ methylphenidate, $O R$ odds ratio, $S M D$ standardized mean difference 
Considering the broader picture emerging from the above-mentioned systematic review, three issues come to the fore. First: speaking of the treatment choices for ADHD in adults, a 'one size fits all' approach does not work - as the drugs differ in terms of efficacy and tolerability profiles. This is a valuable implication, both from the point of view of rank-and-file practitioners and clinical guidelines developers (of note, there has been little consensus among experts about the optimal strategies for sequential pharmacological treatments with psychostimulants and other drugs for ADHD; see Arnett and Stein 2018; Cortese 2020 and Wong et al. 2019). Second: there is a dearth of longer-term trials on pharmacotherapy for ADHD in adults (an important obstacle, since the duration of the therapy in real-life settings usually reflects the chronic course of the condition [Fredriksen et al. 2013]). Third: the certainty of the evidence is relatively low (in other words, the relative effectiveness and safety of the drugs for ADHD has not been determined yet [Balshem et al. 2011]). Having said that, one might ask, is there anything to mention about the clinical effects of the MPH use, beyond the short run?

In fact, there is a growing body of evidence on risks and potential benefits of long-term treatment with MPH in adult patients with ADHD. Accordingly, the authors of the recently published COMPAS trial (The Comparison of Methylphenidate and Psychotherapy in Adult ADHD Study; a multi-centre RCT with over 400 participants) found that after 1 year of treatment, MPH 'maintained' the advantage over placebo in a number of efficacy outcomes (Philipsen et al. 2015). Interestingly enough, the COMPAS team found some evidence for the relative stability of this effect over time, as the termination of treatment did not 'cancel out' entirely the difference between MPH and placebo at the follow-up of 1.5 years (Lam et al. 2019). Nevertheless, this encouraging conclusion should be seen against the backdrop of the broader line of research on maintenance of response and risk of relapse upon discontinuation of MPH. Data from some other RCTs suggest, accordingly, that therapeutic effects of psychostimulants tend to be rather fragile with quite rapid re-emergence of ADHD symptoms once the medication is tapered off (Buitelaar et al. 2015; Huss et al. 2014; Tamminga et al. 2021).

In a recent systematic review of pharmacoepidemiological studies, Chang et al. (2019) found that various modalities of drug therapy for ADHD (involving MPH, other stimulants or atomoxetine) may lead to significant improvements in a number of functional outcomes (i.e., risk of injuries, road traffic accidents and substance use disorders; the therapy was also beneficial in terms of educational achievements). Nevertheless, the picture of the long-term effects of the treatment was not that clear. The authors suggested that studies using within-individual design (i.e., making it possible to compare the clinical status of patients while 'on medication' vs. the periods of 'being unmedicated' or receiving treatment with other classes of drugs - e.g., antidepressants) would facilitate the research on the effectiveness of long-term therapies for ADHD. Unfortunately, this methodological approach has not been widely utilized so far (Chang et al. 2019).

Of particular note, there is emerging evidence to suggest that therapy with psychostimulants (including MPH) is linked to lower rates of antisocial behaviors (Lichtenstein et al. 2012), as well as lower risk of suicide among patients with ADHD (across the age spectrum, from children to middle-aged adults) (Chang et al. 2020). In a meta-analysis of data from 21 placebo-controlled RCTs, MPH was also found to alleviate the ADHD-related emotion regulation deficits, as experienced by adult individuals (SMD, $0.34 ; 95 \%$ CI, 0.23-0.45) (Lenzi et al. 2018).

While the issue of gender differences in terms of MPH effectiveness has been poorly investigated thus far, there is some preliminary data implicating that MPH might be somewhat less efficient in women (Kok et al. 2020; Quinn et al. 2017). Nevertheless, the gender differences (if any) are subtle, and - as such - were not taken into account in the recent treatment guidelines (Young et al. 2020).

\section{Titration and dosage of methylphenidate}

The issue of MPH dose optimization in adults with ADHD is tricky - for a number of reasons.

The confusion begins with the notion of 'optimal treatment' in the context of adult ADHD. As pointed out by Huss et al. (2017), there are two (mutually exclusive) meanings of the 'optimal dosage' with regard to the medications for the condition discussed: either 'the dose above which there is no further improvement', or 'the lowest dose necessary to achieve optimal therapeutic response'. Bearing in mind the marked individual differences in terms of the dose-response pattern (most likely reflecting the pharmacogenetic diversity of patients with ADHD [Bonvicini et al. 2016; Chermá et al. 2017; National Institute for Health and Care Excellence 2018]), coupled with plethora of formulations of MPH (either currently available [Mattingly et al. 2020] or in the pipeline [Cortese et al. 2017]), it is plausible that the art of the treatment with MPH goes beyond 'fine tuning of the dosage'. More than anything else, it has to be tailored to the individual needs and expectations of the patient (Buitelaar et al. 2015; Kooij et al. 2019a, 2010).

Accordingly, it is useful to start with the assumption that the action of the drug should be synchronized with daily habits of the person. In other words, the optimal treatment regimen should cover approximately $12-16 \mathrm{~h}$ a day (Kooij et al. 2010). Since none of the MPH formulations available these days actually meet this criterion, patients often find it beneficial to combine a long-acting MPH with a shorteracting 'version' of the drug. Bearing in mind significant 
individual differences with respect to optimal dose requirements, titration of MPH is essentially a process of trial-anderror (Cortese 2020; Huss et al. 2017; Kooij 2013; Volkow and Swanson 2013).

There is general consensus among experts that the strategic goal of treatment with MPH is to make sure that the medication works all day long (in order to make the patient less likely to experience rebound symptoms of ADHD, once MPH wears off) (Cortese 2020; Faraone et al. 2015; Kooij 2013; Mattingly et al. 2020). The tactics, however, should be flexible. In this respect, duration and onset of action of the available MPH formulations (see Table 6) are the key variables to be considered while tailoring the treatment plan (Mattingly et al. 2020). Pragmatically speaking, using long-acting MPH twice daily (around 8 a.m. and 15 p.m.) is the 'cornerstone' of pharmacotherapy for adults with ADHD, while shorter-acting formulations might be considered as add-on treatments, making it less likely for a patient to develop rebound symptoms at bedtime. Notably, some patients may find it beneficial to take low doses of short-acting MPH in the evening, in order to become more peaceful and, hence, more likely to fall asleep (Kooij 2013; Mattingly et al. 2020).

In quantitative terms, no optimal titres of MPH have been determined so far (Huss et al. 2017). According to the recommendations by the British Association for Psychopharmacology, 'careful titration and monitoring of side effects is required' (Bolea-Alamañac et al. 2014a, b). More specifically, with regard to the MPH-IR formulation, it was recommended to start with $5 \mathrm{mg}$ twice daily (or equivalent for MPH-ER / OROS), followed by daily or weekly increases (provided that the medication is well tolerated by the patient). In order 'to make the trial-and-error more informed' in terms of titration, some ideas can be borrowed from the field of child and adolescent psychiatry - in particular, from the Dundee ADHD Clinical Care Pathway (DACCP). The DACCP framework is based on a highly structured algorithm, utilizing standard protocols for a routine clinical evaluation of patients with ADHD. As reported by Coghill and Seth (2015), meticulous measurement of ADHD symptoms and adverse events significantly improves the quality of clinical decision-making process - thus making the titration of MPH notably smoother. In this regard, a '4-week, structured dose-optimization schedule' is used for all patients prescribed immediaterelease stimulants or extended-release methylphenidate. The dose is increased from 5 to $20 \mathrm{mg}$ three times per day for immediate-release formulations or equivalent dose for long-acting formulations. Medication is usually initiated

Table 6 An outline of dosing strategies for methylphenidate formulations (approved by the FDA for ADHD in adults)

\begin{tabular}{|c|c|c|c|c|}
\hline Brand name & $\begin{array}{l}\text { Dosing } \\
\text { (times per } \\
\text { day) }\end{array}$ & Onset of effect & $\begin{array}{l}\text { Overall dura- } \\
\text { tion of effect }\end{array}$ & Dose range/provisional maximum dose \\
\hline \multicolumn{5}{|l|}{ Short-acting } \\
\hline Ritalin ${ }^{\circledR}$ & $2-3$ & $1-2 \mathrm{~h}$ & $4 \mathrm{~h}$ & 10-60 mg in divided doses \\
\hline Methylin ${ }^{\circledR}$ & $2-3$ & $1 \mathrm{~h}$ & $4 \mathrm{~h}$ & Provisional maximum dose: $150 \mathrm{mg} /$ day \\
\hline Medikinet $\mathrm{CR} \AA$ & 2 & $5-8 \mathrm{~h}$ & & \\
\hline \multicolumn{5}{|c|}{ Intermediate-acting } \\
\hline Methylin ER® & $2-3$ & n.a & n.a & n.a \\
\hline Ritalin SR® & 1 & $1.5 \mathrm{~h}$ & $8 \mathrm{~h}$ & n.a \\
\hline Metadate ER® & 1 & n.a & $8 \mathrm{~h}$ & n.a \\
\hline \multicolumn{5}{|l|}{ Long-acting } \\
\hline Quillichew ER® & 1 & $45 \min$ & $8 \mathrm{~h}$ & Provisional maximum dose: $150 \mathrm{mg} /$ day \\
\hline Concerta ${ }^{\circledR}$ & $1-2$ & $\begin{array}{l}\text { The immediate-release component } \Rightarrow \text { the first peak } \\
\text { plasma concentration: } 1-2 \mathrm{~h} \text { following the inges- } \\
\text { tion } \\
\text { The slow-release component } \Rightarrow \text { the second peak } \\
\text { plasma concentration: about } 7 \mathrm{~h} \text { following the } \\
\text { ingestion }\end{array}$ & $7-12 \mathrm{~h}$ & \\
\hline Quillivant $\mathrm{XR} \circledast$ & 1 & $45 \min$ & $12 \mathrm{~h}$ & \\
\hline Aptensio $\mathrm{XR}^{\mathrm{TM}}$ & 1 & $1 \mathrm{~h}$ & $12 \mathrm{~h}$ & \\
\hline Jornay PM® & 1 & $8-10 \mathrm{~h}$ & $>12 \mathrm{~h}$ & \\
\hline Adhansia XR® & 1 & $1 \mathrm{~h}$ & $13-16 \mathrm{~h}$ & \\
\hline
\end{tabular}

$A D H D$ attention-deficit/hyperactivity disorder, $E R / X R$ extended release, FDA U.S. Food and Drug Administration, n.a. no data available, SR sustained release

Adapted from Banaschewski et al. (2006), Kooij (2013) and Mattingly et al. (2020) 
with 12-h cover, 7 days a week, without routine drug holidays' (Coghill and Seth 2015; cited verbatim).

While no similar strategy has been devised for adults so far, one might expect the titration process to be less straightforward - e.g., because of co-morbidities and (above all) due to significant variability of the individual walks of life, with corresponding differences in terms of the treatment expectations (Steinbuchel and Greenhill 2020). However, speaking of adjusting the doses of MPH in adults, it is noteworthy that every $10-\mathrm{mg}$ dose increase corresponds with the clinical improvement of about $0.11-0.12$ (as expressed with the SMD values) (Castells et al. 2011). This means that the generic rule of 'start low, go slow' does not necessarily apply to the praxis of therapy with MPH, as the low-tomoderate portions of the medication might turn out to be not effective enough for a significant proportion of adult patients with ADHD (Retz and Retz-Junginger 2014).

Even though there is a considerable body of evidence for the linear dose-response relationship (Cortese et al. 2018), the maximum dose of MPH has not been established as yet. The rule of thumb has it that patients should not be prescribed with MPH at doses exceeding $150 \mathrm{mg} /$ day (Kooij 2013). At the same time, it is worth emphasizing that the 'red line' for further titration is marked by any of the three factors (Coghill et al. 2019; Steinbuchel and Greenhill 2020):

1. No room for additional clinical improvement

2. Intolerable adverse events

3. The fact that the maximum dose limit has already been achieved.

\section{Tolerability and safety: general issues}

In terms of tolerability, a Cochrane review of 11 short-term trials (Epstein et al. 2014) suggests that the loss of appetite with subsequent weight decrease is probably the most significant side effect of IR formulations of MPH. Insomnia, headache, dry mouth, tremor, sweating, anxiety, late-afternoon depression, and irritability were also reported. Individuals receiving long-acting MPH are likely to experience a similar range of adverse events, with nasopharyngitis, headache, decreased appetite, dry mouth, and nausea being the most prevalent symptoms (Ginsberg et al. 2014a). There were also significantly higher rates of insomnia in patients receiving OROS MPH (Adler et al. 2011), as compared to modifiedrelease long-acting formulations (20.7 vs. 3.7\%) (Ginsberg et al. 2014a).

Methylphenidate seems to be relatively safe in the long run, as well. As observed in the oft-cited placebo-controlled COMPAS study, the following side effects were significantly more prevalent in the MPH sample over the 52 weeks of monitoring: decreased appetite (22 vs. $3.8 \%$ ), dry mouth (15 vs. $4.8 \%$ ), heart palpitations (13 vs. 3.3\%), gastrointestinal infections (11 vs. $4.8 \%$ ), agitation (11 vs. $3.3 \%$ ), feeling restless (10 vs. $2.9 \%$ ), hyperhidrosis, tachycardia, weight loss (for each of the three outcomes the difference with the placebo group was 6.3 vs. $1.9 \%$ ), depressed mood (4.9 vs. $1.0 \%$ ), influenza (4.9 vs. $1.0 \%$ ), and acute tonsillitis (4.4 vs. $0.5 \%$ ) (Kis et al. 2020).

While the above-mentioned non-specific adverse events are usually transient and relatively mild (Kooij et al. 2010), their implications for day-to-day clinical practice are subject to debate, fuelled by higher rates of treatment discontinuation due to side effects among patients receiving MPH (in comparison to placebo) (Castells et al. 2013). However, speaking about insomnia, there are reports indicating that there may be a significant relationship between the dose and/ or formulation of MPH (or the dosing schedule) and the likelihood of difficulties falling asleep (Stein et al. 2012; Wynchank et al. 2017).

Methylphenidate was repeatedly shown to increase heart rate and blood pressure (Coghill et al. 2013; Epstein et al. 2014; Martinez-Raga et al. 2013), yet it remains unclear whether adult individuals treated with MPH are at significantly higher risk of serious cardiovascular events (Martinez-Raga et al. 2013; Westover and Halm 2012). While Habel et al. (2011) found no evidence for increased risk of myocardial infarction (MI), sudden cardiac death (SCD), or stroke, a corresponding trial by Schelleman et al. (2012) reported significantly higher rates of SCD/ventricular arrhythmias and stroke in a sample of patients treated with MPH (in comparison to individuals who had not used the medication). However, the absolute risk increase (ARI) values were very small $(0.2-0.4 \%$; see Table 7$)$. There is also early evidence suggesting that MPH may act as a trigger for arrhythmias, particularly in patients with congenital heart diseases (Shin et al. 2016).

While the legal status of psychostimulants as controlled substances is 'firmly established' (e.g., see schedule II of the U.S. Controlled Substances Act [Preuss et al. 2020]), it remains unclear whether in clinical settings MPH should be considered a 'genuine' - even if only potential — drug of abuse. Notably, the authors of the two long-term naturalistic studies did not find any significant relationship between treatment with psychostimulants (including MPH) and subsequent substance use disorders in adults with ADHD (Biederman et al. 2008; Faraone et al. 2007) (for an overview, see the article by Fredriksen et al. [2013]). This conclusion remains in line with the seminal paper by Volkow and Swanson (2003), who noticed that abuse liability of MPH depends primarily on the route of administration - with expeditious rise of DA levels, once the medication is snorted or injected (admittedly, these scenarios are very remote from the real-life context of providing treatment for patients with ADHD; see the section 'Acute 
Table 7 Risk of serious cardiovascular events in methylphenidate users (adapted from Schelleman et al. [2012])
Fig. 1 Structures of the four configurational (and two stereo-) isomers of the methylphenidate (Adapted from Markowitz et al. (2003a))

\begin{tabular}{lllll}
\hline Outcome & \multicolumn{2}{l}{ Number of events } & RR (95\% CI) & ARI (95\% CI)* \\
\cline { 2 - 3 } & $\begin{array}{l}\text { Individuals } \\
\text { treated with MPH } \\
(N=43,999)\end{array}$ & $\begin{array}{l}\text { Individuals not treated } \\
\text { with MPH }(N=175,955)\end{array}$ & \\
\hline SCD / VA & 54 & 432 & $2.73(2.02-3.70)$ & $0.4 \%$ \\
Stroke & 54 & 796 & $1.40(1.05-1.87)$ & $0.2 \%$ \\
MI & 47 & 928 & $1.09(0.81-1.48)$ & NS \\
$\begin{array}{l}\text { Composite out- } \\
\text { come of MI or } \\
\text { stroke }\end{array}$ & 98 & 1642 & $1.25(1.01-1.54)$ & $0.2 \%$ \\
All-cause death & 854 & & & \\
\hline
\end{tabular}

$A R I$ absolute risk increase, $C I$ confidence interval, $M I$ myocardial infarction, $N S$ not significant, $R R$ relative risk, $S C D$ sudden cardiac death, $V A$ ventricular arrhythmia

* As calculated by one of the co-authors of this paper (RRJ)

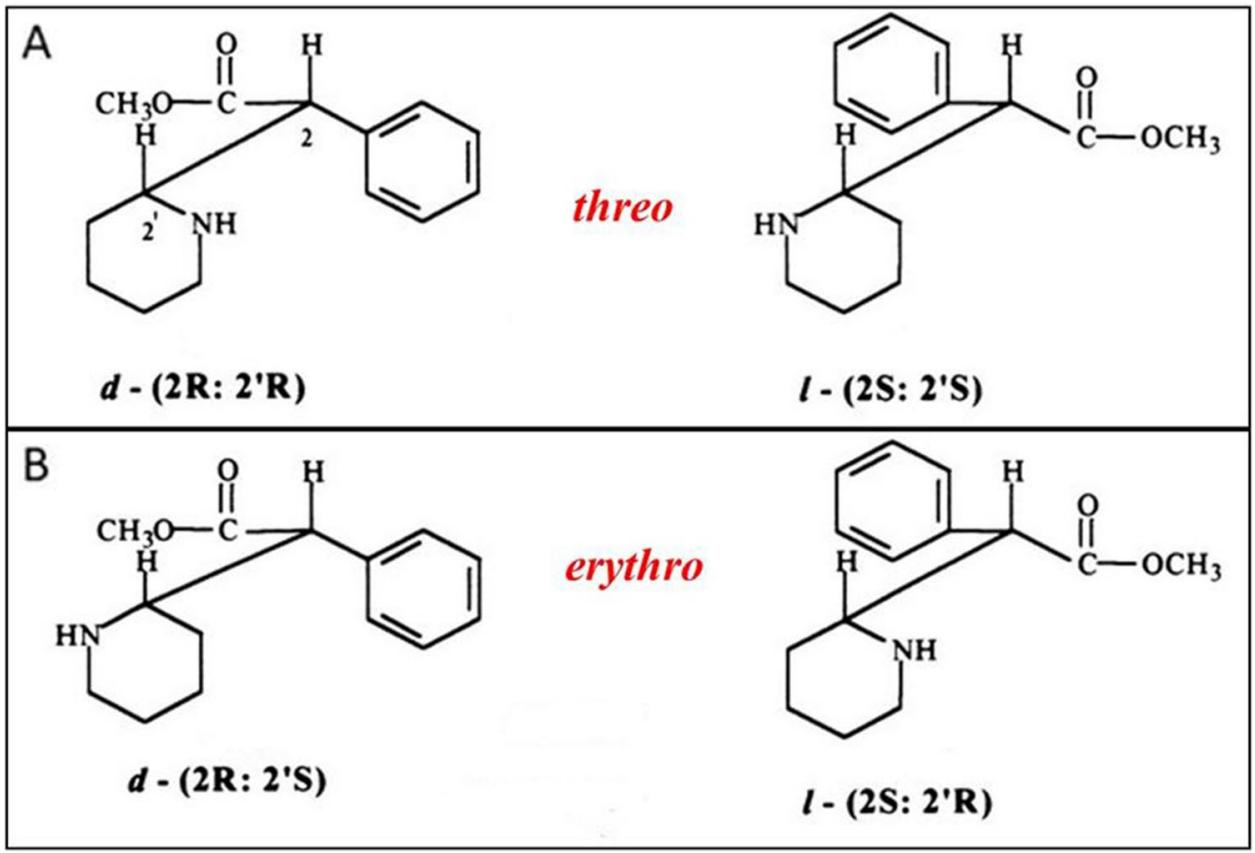

toxicity' below). Quite the opposite, oral formulations of MPH ensure gradual increase of dopaminergic activity, thus keeping 'slow but sure' pace of the sustained response of DA-releasing neurons and - coupled with slow clearance of MPH from the brain - making it unlikely to develop a vicious circle of 'dopaminergic hits followed by the misery of craving'. In other words, the oral formulations ensure slow entry of MPH into the brain - the hallmark of therapeutic utility, instead of abuse liability. Since there is no dose-response relationship between the medication intake and feeling 'high' following the intake of oral preparations of MPH (due to the slow increase of the drug concentration in the brain - as opposed to the aftermath of either snorting or injecting MPH for recreational purposes), oral formulations are considered safe in terms of the risk of developing addiction (Volkow and Swanson 2003).

Nevertheless, the authors of the recent pharmacovigilance studies performed in Denmark (Pottegård et al. 2013) and France (Pauly et al. 2018) detected a long-term, upward trend in MPH dose adjustments (with the mean 'peak' of $89.6 \mathrm{mg}$ daily among the cluster of 25- to 49-year-old participants of the French cohort [Pauly et al. 2018]). It remains to be determined whether these findings reflect a build-up of tolerance to MPH.

In terms of other potential safety issues, it is worth mentioning that treatment with MPH probably does not yield significant risk of developing psychosis (Chang et al. 2019; Moran et al. 2019). Speaking of a broader range of longterm neuropsychiatric outcomes, the authors of the recent 


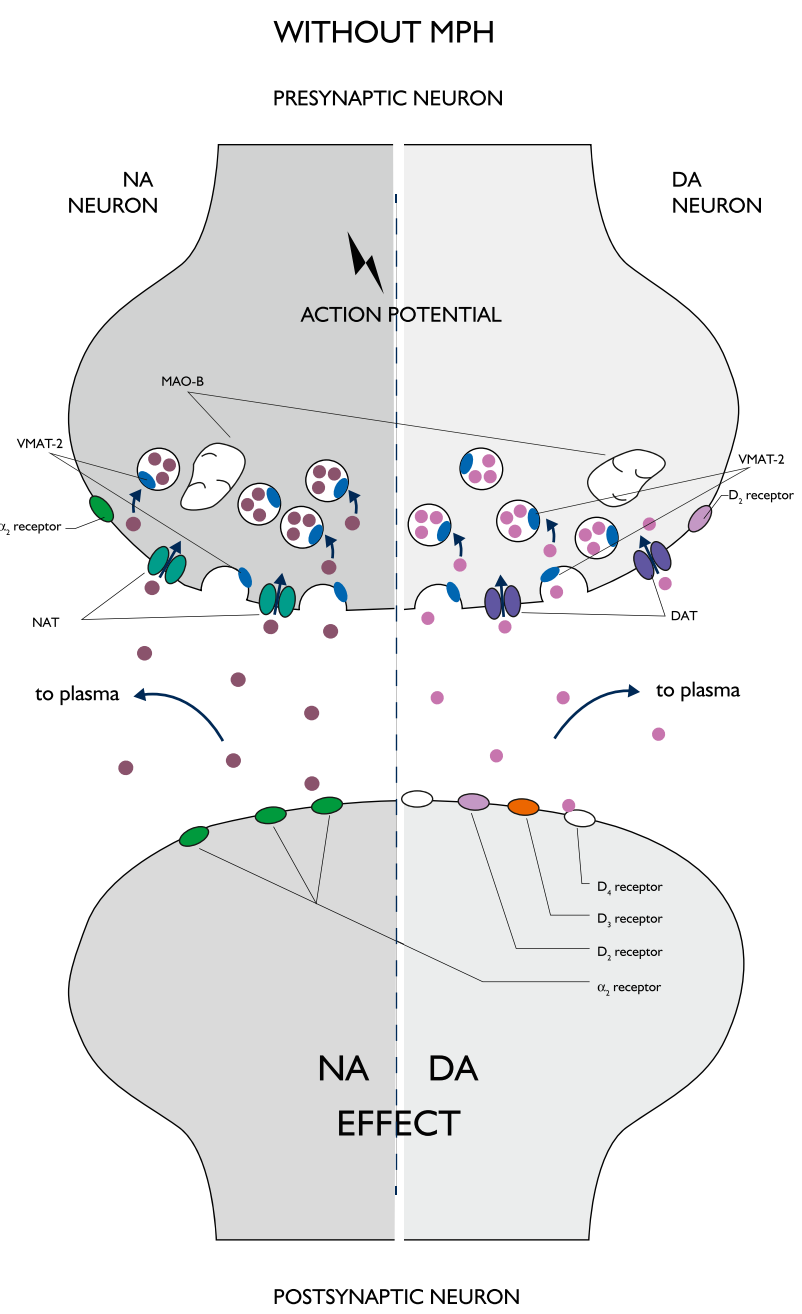

Fig. 2 An outline of the mechanisms of action of methylphenidate

ADDUCE (Attention Deficit / Hyperactivity Disorder Drugs Use Chronic Effects) study found that the data available is as heterogenous as inconclusive. While the treatment with MPH does not seem to elevate the risk of some common psychiatric symptoms (i.e., depressed mood, anxiety and irritability), 'studies exploring dosing and timing of MPH are warranted in this area' (Krinzinger et al. 2019; cited verbatim). Also, the available evidence does not support the hypothesis linking therapy with psychostimulants to higher risk of tic disorders among patients with ADHD (Krinzinger et al. 2019) (even though MPH might 'exacerbate tics in individual cases'; for details, see the Cochrane review by Osland et al. 2018).

Let us close this passage with an important practical note: in cases of ADHD coexisting with hypertension, hyperthyroidism, glaucoma or some cardiac issues (i.e., angina, arrhythmias and hypertrophic cardiomyopathy), neither MPH nor other stimulants should be considered the drugs
WITH MPH

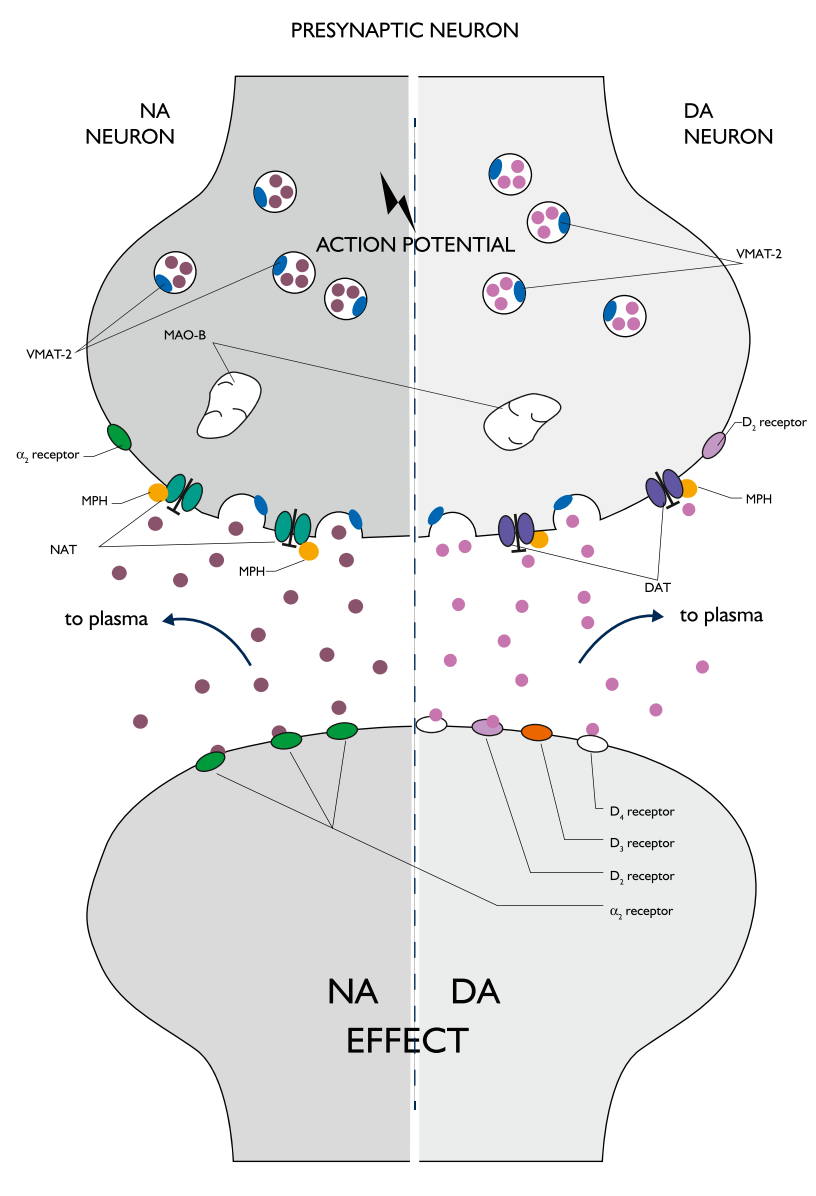

POSTSYNAPTIC NEURON

of choice. In fact, the above-mentioned medical conditions are deemed relative contra-indications for treatment with psychostimulants (Kooij et al. 2010).

\section{Acute toxicity}

There is limited data on acute toxicity of MPH in humans. However, the available evidence suggests that the risk of life-threatening adverse events among individuals who overdosed MPH is very low (Bruggisser et al. 2011; Hondebrink et al. 2015; Rietjens et al. 2017).

The most commonly reported signs of MPH overdose are drowsiness, tachycardia, dry mouth, headache, and agitation (Hondebrink et al. 2015). This finding is consistent with theoretical considerations suggesting that MPH toxicity represents a sympathomimetic syndrome driven by 'excessive blockade' of NAT, leading to overstimulation of both $\alpha$ - and $\beta$-adrenergic receptors (Spiller 
et al. 2013). Therefore, from the clinical standpoint, dopaminergic mechanisms behind MPH toxicity seem to be less important in comparison with the noradrenergic components (Rietjens et al. 2017).

In the vast majority (that is, around 90\%) of cases, symptoms related to MPH toxicity are mild, transient, and self-limiting. More severe outcomes (e.g., psychosis or arrhythmia) are much rarer (Hondebrink et al. 2015). Nevertheless, once they develop, the patient should be treated just like any other individual who overdosed stimulants (in other words, the general rules for clinical management of amphetamine poisoning do apply) (Spiller et al. 2013). Having said that, the MPH dose threshold for hospital referral remains subject to controversy - making it unclear 'who actually requires evaluation at the emergency department'. The postulated cut-off scores suggestive for clinically significant MPH intoxication vary between 2 and $3 \mathrm{mg} / \mathrm{kg}$ (as discussed in depth by Hondebrink et al. 2015 and Scharman et al. 2007); also, the laboratory alert level for the MPH blood concentration was recently set at $50 \mathrm{ng} / \mathrm{ml}$ (Hiemke et al. 2018). As a rule of thumb, all patients who developed hallucinations, abnormal movements, or chest pain subsequently to MPH ingestion should be referred to a hospital for further evaluation (Scharman et al. 2007). The quantitative (laboratory) measures of the presumed MPH toxicity seem to be much less certain, as there is no clear dose-effect relationship in this case (Rietjens et al. 2017) and, first and foremost, the optimal therapeutic range of MPH doses has not been determined yet (Cortese 2020; Cortese et al. 2018) (see 'Discussion').

Of particular note, the route of administration of MPH is an important determinant of the risk of poisoning. Accordingly, there is evidence to suggest that $\mathrm{MPH}$, if administered intravenously, may lead to some severe toxic reactions (e.g., local ischemia and skin necrosis). It seems to be the case that individuals who abuse MPH in oral or nasal forms are not subject to the risks of that kind (Bruggisser et al. 2011).

\section{Tolerability and safety of methylphenidate in specific populations}

\section{The elderly}

There is very limited data regarding safety of MPH among older adults. However, the authors of a recently published observational study (encompassing 113 individuals aged $\geq 55$ years, who were receiving treatment for ADHD at a specialized outpatient clinic in the Netherlands) found that the risk-to-benefit did not seem to differ from the population of younger adults. Nevertheless, the results need to be replicated in rigorously designed and meticulously conducted RCTs (Michielsen et al. 2020).

\section{Pregnant or breastfeeding women}

Even though there is an increasing trend of prescribing stimulants during pregnancy and breastfeeding, safety data for this practice is scarce (Bolea-Alamanac et al. 2014; Haervig et al. 2014; McAllister-Williams et al. 2017). This is why, as a precaution, MPH and related medications are not recommended for pregnant or breastfeeding women (Young et al. 2020).

While MPH does not seem to have teratogenic properties, there are concerns regarding risk of miscarriages, cardiac malformations, deceleration of fetal growth, as well as preterm birth and placenta-associated pregnancy complications (e.g., preeclampsia). However, the available evidence is largely inconclusive, since the absolute risk of the above-mentioned adverse outcomes remains hard to estimate (Baker and Freeman 2018; Koren et al. 2020; Li et al. 2020; Poulton et al. 2018).

Notably, breastfeeding is not considered as contraindication for treatment with MPH, since just a very small fraction of the drug is secreted in milk (making MPH undetectable in the infant's serum) (Ornoy 2018; U.S. National Library of Medicine 2020).

\section{Discussion}

In this paper, we provided an overview of the current knowledge about MPH in the treatment of adult patients with ADHD. We covered a broad range of issues, from the basic pharmacology to specific clinical considerations. Admittedly, a number of important items (e.g., the rationale of using MPH in ADHD co-occurring with substance use disorders [Crunelle et al. 2018; Skoglund et al. 2017], and the potential role of $\mathrm{MPH}$ as a cognitive enhancer [Linssen et al. 2014; Westbrook et al. 2020]) remained beyond the scope of this article.

Methylphenidate acts primarily as the DA reuptake inhibitor, at the same time securing the balance between the availability of intra-synaptic DA and the intracellular pool of the neurotransmitter (through the interactions with VMAT-2). Therefore, it is devoid of the neurotoxic properties - unlike the DA-releasing psychostimulants (e.g., methamphetamine) (Fleckenstein et al. 2009; German et al. 2015). The relatively slow entry of MPH into the brain, coupled with the likewise slow pace of the clearance, makes the drug relatively safe in terms of the risk of abuse (Volkow et al. 1995; Volkow and Swanson 2003). On a more general note, one might hypothesize that MPH and other stimulants bear the status of proverbial 'drugs 
for ADHD' - and here is why. Given the fact that ADHD represents a failure to deactivate DMN during low-salient tasks (i.e., slow, boring and unrewarding chores; in other words - the heavy duties of everyday life), MPH was notably found to be able to 'switch the DMN off' in the above-mentioned situations, thus increasing salience of stimuli that would otherwise end up as fuel for MW (Bozhilova et al. 2018; Liddle et al. 2011).

While reading the closing section of a paper on clinical pharmacology, one might expect a succinct discussion of 'pros and cons of the medication in question'. However, when pondering about the rationale of using MPH for ADHD in adults, the conclusions must be drawn against the backdrop of numerous paradoxes (clinical and cultural alike) and seemingly loose ends in the research data. Here, we have the drug known for nearly 80 years and still quite 'vague' (Pliszka 2019; Wenthur 2016); notable for its effectiveness and yet 'controversial' (Cortese et al. 2018); relatively safe and mired by 'stigma by association' with illicit and addictive psychostimulants (e.g., methamphetamine and cocaine) (Kooij et al. 2010; Volkow and Swanson 2003). On the other hand, the persistent view of ADHD as a "childhood disorder of dubious validity' further contributes to the problem of stigma (Faraone 2020; Masuch et al. 2019; Mueller et al. 2012), making the road to adequate diagnosis and treatment even more bumpy for adult individuals. And while 'loose ends' are hardly unique in psychiatric research in general (Alda and Hajek 2012), there are, in our opinion, some specific aspects making it particularly challenging to get one's head around the treatment objectives in ADHD. Precisely, ADHD is an umbrella term for a set of trait-like features and a developmental trajectory alike (Asherson et al. 2016; Franke et al. 2018; Fredriksen et al. 2013). For this reason, the day-to-day adverse consequences of ADHD are not limited to various social, academic, and occupational circumstances of the individual's life (Roselló et al. 2020). In fact, as neatly coined by Faraone et al. (2015), 'the disorder directly affects perceptions of well-being' - the statement which, from the standpoint of everyday clinical practice, translates into a mind-boggling spectrum of patient-important outcomes (Bölte et al. 2018). Therefore, it is not possible to evaluate the utility of MPH (or any other medication for ADHD) on the grounds of impact on the core symptoms only; nor is it plausible to pre-define any 'strict indications' for initiating the pharmacotherapy. In general terms, treatment choices for ADHD in adults are driven by the accompanying functional impairment and the individual preferences of the patient. Of particular note, as emphasized in the recent 'Canadian ADHD Practice Guidelines' (2018): 'the high morbidity of ADHD makes it important that we also weigh the risk of not treating ADHD'. This idea was further elucidated by Fredriksen et al. (2013): 'Ultimately, the treatment goal for ADHD, whether initiated during childhood or adulthood should be, not only temporary symptom relief, but also the establishment of a more favorable long-term developmental trajectory'.

Methylphenidate along with other stimulants (i.e., amphetamine derivatives) is recommended as the medication of choice for ADHD in adults (National Institute for Health and Care Excellence 2018; Wong et al. 2019). Even though MPH seems to lag behind amphetamines in terms of efficacy against the core ADHD symptoms (Cortese et al. 2018), the SMD value of 0.5 denotes moderate (and certainly decent - as compared to numerous other psychiatric and non-psychiatric drugs [Leucht et al. 2012]) improvement. In addition, it is hard to overemphasize the importance of the recent finding by Chang et al. (2020), suggesting that treatment with psychostimulants (including MPH) is linked to lower rates of suicide attempts in patients with ADHD across the age spectrum.

The most common MPH-related adverse events are loss of appetite and insomnia (with the risk of the latter moderated by the formulation used and the treatment regimen Ginsberg et al. 2014a; Stein et al. 2012; Wynchank et al. 2017). Of note, the side effects are usually relatively mild and transitory (or at least clinically manageable). Therefore, the methodological controversies around the rationale behind treatment with MPH seem to be driven primarily by the lack of consensus about the optimal ways of evaluating the relative weight of the outcomes (Cortese 2018; Guyatt et al. 2011). Nevertheless, given the recent developments around the research on the core outcome sets for ADHD, this limitation may soon become obsolete (Bölte et al. 2018).

Still, the available evidence base on the long-term outcomes of treatment with MPH is too patchy to draw firm conclusions regarding the overall risk-to-benefit balance (Cortese 2020; Faltinsen et al. 2019; Franke et al. 2018; Volkow and Swanson 2013). Interestingly enough, it was recently discovered that the therapeutic effects of MPH in adults with ADHD might be relatively stable over time (in spite of the prior treatment discontinuation). The mechanisms behind this phenomenon are unknown (Lam et al. 2019). While the finding remains in line with the hypothesis of 'MPH-related improvement in neurodevelopmental trajectory' (Fredriksen et al. 2013), it is hard to reconcile with the 'on-off' pharmacokinetics of MPH (Patrick et al. 2005).

The current clinical guidelines provide limited support regarding the specific strategies of MPH titration in adult patients (Bolea-Alamañac et al. 2014a, b; Cortese et al. 2018; Huss et al. 2017; National Institute for Health and Care Excellence 2018). It is hardly surprising, given the paradox that the optimal dosage regimen for ADHD (in children and adults alike) has not been determined yet (Ching et al. 2019; Cortese et al. 2018; Lam et al. 2019). Notably, the network meta-analysis by Cortese et al. (2018) provided with data suggestive for the linear dose-response 
relationship in adults receiving MPH, yet it is unclear how this finding would specifically translate into clinical practice (Arnett and Stein 2018). In the position paper by members of the International Multicentre Persistent ADHD Collaboration, it was implied that 'doses around $1 \mathrm{mg} / \mathrm{kg}$ [per body mass] of methylphenidate are correlated with better efficacy, yet are rarely achieved in studies of adult patients' (Franke et al. 2018).

Let us conclude with an epidemiological note about ADHD in adults as an important 'blind spot' in psychiatry. Being an important source of chronic stress, ADHD is a significant risk factor for anxiety and depressive disorders (Ahnemark et al. 2018), and while psychiatric comorbidities are a rule rather than an exception among patients with ADHD (Franke et al. 2018; Katzman et al. 2017; Kooij et al. 2019a), they do not necessarily represent 'coexisting-butseparate' clinical issues. Actually, accompanying mental disorders oftentimes reflect downstream effects of ADHD. There is substantial body of evidence to suggest that unrecognized or misdiagnosed ADHD is an important contributor to the problem of suboptimal treatment outcomes in the broad population of patients with mental health issues (Ginsberg et al. 2014b). Hence, there is no doubt that adults with ADHD should be adequately treated, while MPH appears to be a relatively effective and safe therapeutic option.

Acknowledgements The authors wish to thank Magdalena Kobus for proofreading the manuscript, and Katarzyna Opiela for managing the artwork.

Author contribution R.R.J. and M.S.-K. contributed by putting forward the concept and design of the review paper; they also performed literature searches, evaluated the quality of the available evidence, and wrote the manuscript. They also revised the first draft of the paper. In this respect, R.R.J. and M.S.-K were the principal authors and editors of the clinical and pre-clinical sections of the paper, respectively. E.S. conducted pharmacology literature search and wrote the pharmacological sections of the first draft of the manuscript.

Data availability Not applicable (given the fact that no new data were created or analyzed for the purpose of this review paper).

\section{Declarations}

Ethics approval and consent to participate Not applicable.

Consent for publication Not applicable.

Conflict of interest The authors declare no competing interests.

Open Access This article is licensed under a Creative Commons Attribution 4.0 International License, which permits use, sharing, adaptation, distribution and reproduction in any medium or format, as long as you give appropriate credit to the original author(s) and the source, provide a link to the Creative Commons licence, and indicate if changes were made. The images or other third party material in this article are included in the article's Creative Commons licence, unless indicated otherwise in a credit line to the material. If material is not included in the article's Creative Commons licence and your intended use is not permitted by statutory regulation or exceeds the permitted use, you will need to obtain permission directly from the copyright holder. To view a copy of this licence, visit http://creativecommons.org/licenses/by/4.0/.

\section{References}

Adler LA, Orman C, Starr HL, Silber S, Palumbo J, Cooper K, Berwaerts J, Harrison DD (2011) Long-term safety of OROS methylphenidate in adults with attention-deficit/hyperactivity disorder: an open-label, dose-titration, 1-year study. J Clin Psychopharmacol 31:108-114

Ahnemark E, Di Schiena M, Fredman AC, Medin E, Söderling JK, Ginsberg Y (2018) Health-related quality of life and burden of illness in adults with newly diagnosed attention-deficit/hyperactivity disorder in Sweden. BMC Psychiatry 18:223

Alda M, Hajek T (2012) Loose ends of psychiatric research. J Psychiatry Neurosci 37:367-368

American Psychiatric Association (2013) Diagnostic and Statistical Manual of Mental Disorders, Fifth Edition. American Psychiatric Association, Arlington, VA

Andrews GD, Lavin A (2006) Methylphenidate increases cortical excitability via activation of alpha- 2 noradrenergic receptors. Neuropsychopharmacology 31:594-601

Arnett A, Stein M (2018) Refining treatment choices for ADHD. Lancet Psychiatry 5:691-692

Asherson P, Buitelaar J, Faraone SV, Rohde LA (2016) Adult attentiondeficit hyperactivity disorder: key conceptual issues. Lancet Psychiatry 3:568-578

Baker AS, Freeman MP (2018) Management of attention deficit hyperactivity disorder during pregnancy. Obstet Gynecol Clin North Am 45:495-509

Balshem H, Helfand M, Schünemann HJ, Oxman AD, Kunz R, Brożek J, Vist GE, Falck-Ytter Y, Meerpohl J, Norris S, Guyatt GH (2011) GRADE guidelines: 3. Rating the quality of evidence. J Clin Epidemiol 64:401-406

Banaschewski T, Coghill D, Santosh P, Zuddas A, Asherson P, Buitelaar J, Danckaerts M, Döpfner M, Faraone SV, Rothenberger A, Sergeant J, Steinhausen HC, Sonuga-Barke EJ, Taylor E (2006) Long-acting medications for the hyperkinetic disorders. A systematic review and European treatment guideline. Eur Child Adolesc Psychiatry 15:476-495

Bartl J, Palazzesi F, Parrinello M, Hommers L, Riederer P, Walitza S, Grünblatt E (2017) The impact of methylphenidate and its enantiomers on dopamine synthesis and metabolism in vitro. Prog Neuropsychopharmacol Biol Psychiatry 79:281-288

Beheshti A, Chavanon ML, Christiansen H (2020) Emotion dysregulation in adults with attention deficit hyperactivity disorder: a meta-analysis. BMC Psychiatry 20:120

Bentley J, Snyder F, Brown SD, Brown RW, Pond BB (2015) Sex differences in the kinetic profiles of d- and 1- methylphenidate in the brains of adult rats. Eur Rev Med Pharmacol Sci 19:2514-2519

Besnard J, Ruda GF, Setola V, Abecassis K, Rodriguiz RM, Huang XP, Norval S, Sassano MF, Shin AI, Webster LA, Simeons FR, Stojanovski L, Prat A, Seidah NG, Constam DB, Bickerton GR, Read KD, Wetsel WC, Gilbert IH, Roth BL, Hopkins AL (2012) Automated design of ligands to polypharmacological profiles. Nature 492:215-220

Biederman J, Monuteaux MC, Spencer T, Wilens TE, Macpherson HA, Faraone SV (2008) Stimulant therapy and risk for subsequent substance use disorders in male adults with ADHD: a 
naturalistic controlled 10-year follow-up study. Am J Psychiatry 165:597-603

Biederman J, Lanier J, DiSalvo M, Noyes E, Fried R, Woodworth KY, Biederman I, Faraone SV (2019) Clinical correlates of mind wandering in adults with ADHD. J Psychiatr Res 117:15-23

Boedhoe PSW, van Rooij D, Hoogman M, Twisk JWR, Schmaal L, Abe Y, Alonso P, Ameis SH, Anikin A, Anticevic A, Arango C, Arnold PD, Asherson P, Assogna F, Auzias G, Banaschewski T, Baranov A, Batistuzzo MC, Baumeister S, Baur-Streubel R, Behrmann M, Bellgrove MA, Benedetti F, Beucke JC, Biederman J, Bollettini I, Bose A, Bralten J, Bramati IE, Brandeis D, Brem S, Brennan BP, Busatto GF, Calderoni S, Calvo A, Calvo R, Castellanos FX, Cercignani M, Chaim-Avancini TM, Chantiluke KC, Cheng Y, Cho KIK, Christakou A, Coghill D, Conzelmann A, Cubillo AI, Dale AM, Dallaspezia S, Daly E, Denys D, Deruelle C, Di Martino A, Dinstein I, Doyle AE, Durston S, Earl EA, Ecker C, Ehrlich S, Ely BA, Epstein JN, Ethofer T, Fair DA, Fallgatter AJ, Faraone SV, Fedor J, Feng X, Feusner JD, Fitzgerald J, Fitzgerald KD, Fouche JP, Freitag CM, Fridgeirsson EA, Frodl T, Gabel MC, Gallagher L, Gogberashvili T, Gori I, Gruner P, Gürsel DA, Haar S, Haavik J, Hall GB, Harrison NA, Hartman CA, Heslenfeld DJ, Hirano Y, Hoekstra PJ, Hoexter MQ, Hohmann S, Høvik MF, Hu H, Huyser C, Jahanshad N, Jalbrzikowski M, James A, Janssen J, Jaspers-Fayer F, Jernigan TL, Kapilushniy D, Kardatzki B, Karkashadze G, Kathmann N, Kaufmann C, Kelly C, Khadka S, King JA, Koch K, Kohls G, Konrad K, Kuno M, Kuntsi J, Kvale G, Kwon JS, Lazaro L, Lera-Miguel S, Lesch KP, Hoekstra L, Liu Y, Lochner C, Louza MR, Luna B, Lundervold AJ, Malpas CB, Marques P, Marsh R, Martinez-Zalacain I, Mataix-Cols D, Mattos P, McCarthy H, McGrath J, Mehta MA, Menchón JM, Mennes M, Martinho MM, Moreira PS, Morer A, Morgado P, Muratori F, Murphy CM, Murphy DGM, Nakagawa A, Nakamae T, Nakao T, Namazova-Baranova L, Narayanaswamy JC, Nicolau R, Nigg JT, Novotny SE, Nurmi EL, Weiss EO, O'Gorman Tuura RL, O'Hearn K, O'Neill J, Oosterlaan J, Oranje B, Paloyelis Y, Parellada M, Pauli P, Perriello C, Piacentini J, Piras F, Piras F, Plessen KJ, Puig O, RamosQuiroga JA, Reddy YCJ, Reif A, Reneman L, Retico A, Rosa PGP, Rubia K, Rus OG, Sakai Y, Schrantee A, Schwarz L, Schweren LJS, Seitz J, Shaw P, Shook D, Silk TJ, Simpson HB, Skokauskas N, Soliva Vila JC, Solovieva A, Soreni N, SorianoMas C, Spalletta G, Stern ER, Stevens MC, Stewart SE, Sudre G, Szeszko PR, Tamm L, Taylor MJ, Tolin DF, Tosetti M, Tovar-Moll F, Tsuchiyagaito A, van Erp TGM, van Wingen GA, Vance A, Venkatasubramanian G, Vilarroya O, VivesGilabert Y, von Polier GG, Walitza S, Wallace GL, Wang Z, Wolfers T, Yoncheva YN, Yun JY, Zanetti MV, Zhou F, Ziegler GC, Zierhut KC, Zwiers MP, the ENIGMA ADHD working group, the ENIGMA ASD working group, the ENIGMA OCD working group, Thompson PM, Stein DJ, Buitelaar J, Franke B, van den Heuvel OA, (2020) Subcortical brain volume, regional cortical thickness, and cortical surface area across disorders: findings from the ENIGMA ADHD, ASD, and OCD Working Groups. Am J Psychiatry 177:834-843

Boland H, DiSalvo M, Fried R, Woodworth KY, Wilens T, Faraone SV, Biederman J (2020) A literature review and meta-analysis on the effects of ADHD medications on functional outcomes. $J$ Psychiatr Res 123:21-30

Bolea-Alamañac B, Nutt DJ, Adamou M, Asherson P, Bazire S, Coghill D, Heal D, Muller U, Nash J, Santosh P, Sayal K, Sonuga-Barke E, Young SJ, Association B, for Psychopharmacology, (2014a) Evidence-based guidelines for the pharmacological management of attention deficit hyperactivity disorder: update on recommendations from the British Association for Psychopharmacology. J Psychopharmacol 28:179-203
Bolea-Alamañac BM, Green A, Verma G, Maxwell P, Davies SJ (2014b) Methylphenidate use in pregnancy and lactation: a systematic review of evidence. Br J Clin Pharmacol 77:96-101

Bölte S, Mahdi S, Coghill D, Gau SS, Granlund M, Holtmann M, Karande S, Levy F, Rohde LA, Segerer W, de Vries PJ, Selb M (2018) Standardised assessment of functioning in ADHD: consensus on the ICF Core Sets for ADHD. Eur Child Adolesc Psychiatry 27:1261-1281

Bonvicini C, Faraone SV, Scassellati C (2016) Attention-deficit hyperactivity disorder in adults: a systematic review and meta-analysis of genetic, pharmacogenetic and biochemical studies. Mol Psychiatry 21:872-884

Bozhilova NS, Michelini G, Kuntsi J, Asherson P (2018) Mind wandering perspective on attention-deficit/hyperactivity disorder. Neurosci Biobehav Rev 92:464-476

Breda V, Rohde LA, Menezes AMB, Anselmi L, Caye A, Rovaris DL, Vitola ES, Bau CHD, Grevet EH (2020) The neurodevelopmental nature of attention-deficit hyperactivity disorder in adults. $\mathrm{Br} \mathbf{J}$ Psychiatry: $1-8$.

Brouwers MC, Kho ME, Browman GP, Burgers JS, Cluzeau F, Feder G, Fervers B, Graham ID, Grimshaw J, Hanna SE, Littlejohns P, Makarski J, Zitzelsberger L, AGREE Next Steps Consortium (2010) AGREE II: advancing guideline development, reporting and evaluation in health care. CMAJ 182: E839-42

Bruggisser M, Bodmer M, Liechti ME (2011) Severe toxicity due to injected but not oral or nasal abuse of methylphenidate tablets. Swiss Med Wkly 141: w13267.

Buitelaar J, Asherson P, Soutullo C, Colla M, Adams DH, Tanaka Y, Haynes VS, Escobar R, Upadhyaya H (2015) Differences in maintenance of response upon discontinuation across medication treatments in attention-deficit/hyperactivity disorder. Eur Neuropsychopharmacol 25:1611-1621

Canadian ADHD Resource Alliance (CADDRA) (2018) Canadian ADHD Practice Guidelines, 4th edn. CADDRA, Toronto ON

Castells X, Ramos-Quiroga JA, Rigau D, Bosch R, Nogueira M, Vidal X, Casas M (2011) Efficacy of methylphenidate for adults with attention-deficit hyperactivity disorder: a meta-regression analysis. CNS Drugs 25:157-169

Castells X, Cunill R, Capellà D (2013) Treatment discontinuation with methylphenidate in adults with attention deficit hyperactivity disorder: a meta-analysis of randomized clinical trials. Eur J Clin Pharmacol 69:347-356

Chan YP, Swanson JM, Soldin SS, Thiessen JJ, Macleod SM, Logan W (1983) Methylphenidate hydrochloride given with or before breakfast: II. Effects on plasma concentration of methylphenidate and ritalinic acid. Pediatrics 72:56-59

Chang Z, Ghirardi L, Quinn PD, Asherson P, D’Onofrio BM, Larsson H (2019) Risks and benefits of attention-deficit/hyperactivity disorder medication on behavioral and neuropsychiatric outcomes: a qualitative review of pharmacoepidemiology studies using linked prescription databases. Biol Psychiatry 86:335-343

Chang Z, Quinn PD, O'Reilly L, Sjölander A, Hur K, Gibbons R, Larsson H, D'Onofrio BM (2020) Medication for attention-deficit/ hyperactivity disorder and risk for suicide attempts. Biol Psychiatry $88: 452-458$

Chermá MD, Josefsson M, Rydberg I, Woxler P, Trygg T, Hollertz O, Gustafsson PA (2017) Methylphenidate for treating ADHD: a naturalistic clinical study of methylphenidate blood concentrations in children and adults with optimized dosage. Eur J Drug Metab Pharmacokinet 42:295-307

Childress AC, Komolova M, Sallee FR (2019) An update on the pharmacokinetic considerations in the treatment of ADHD with longacting methylphenidate and amphetamine formulations. Expert Opin Drug Metab Toxicol 15:937-974

Ching C, Eslick GD, Poulton AS (2019) Evaluation of methylphenidate safety and maximum-dose titration rationale in 
attention-deficit/hyperactivity disorder: a meta-analysis. JAMA Pediatr 173:630-639

Christoff K, Irving ZC, Fox KC, Spreng RN, Andrews-Hanna JR (2016) Mind-wandering as spontaneous thought: a dynamic framework. Nat Rev Neurosci 17:718-731

Coghill D, Seth S (2015) Effective management of attention-deficit/ hyperactivity disorder (ADHD) through structured re-assessment: the Dundee ADHD Clinical Care Pathway. Child Adolesc Psychiatry Ment Health 9:52

Coghill D, Banaschewski T, Zuddas A, Pelaz A, Gagliano A, Doepfner M (2013) Long-acting methylphenidate formulations in the treatment of attention-deficit/hyperactivity disorder: a systematic review of head-to-head studies. BMC Psychiatry 13:237

Coghill D, Chen W, Silva D (2019) Organizing and delivering treatment for ADHD. In: Rohde LA, Buitelaar JK, Gerlach M, Faraone S (eds) The World Federation of ADHD Guide. World Federation of ADHD, Porto Alegre - São Paulo pp 83-109

Cortese S (2018) Are the effects of methylphenidate uncertain? Ir J Psychol Med 35:163-167

Cortese S (2020) Pharmacologic treatment of attention deficit-hyperactivity disorder. N Engl J Med 383:1050-1056

Cortese S, D'Acunto G, Konofal E, Masi G, Vitiello B (2017) New formulations of methylphenidate for the treatment of attentiondeficit/hyperactivity disorder: pharmacokinetics, efficacy, and tolerability. CNS Drugs 31:149-160

Cortese S, Adamo N, Del Giovane C, Mohr-Jensen C, Hayes AJ, Carucci S, Atkinson LZ, Tessari L, Banaschewski T, Coghill D, Hollis C, Simonoff E, Zuddas A, Barbui C, Purgato M, Steinhausen HC, Shokraneh F, Xia J, Cipriani A (2018) Comparative efficacy and tolerability of medications for attention-deficit hyperactivity disorder in children, adolescents, and adults: a systematic review and network meta-analysis. Lancet Psychiatry 5:727-738

Costa A, Riedel M, Pogarell O, Menzel-Zelnitschek F, Schwarz M, Reiser M, Moller HJ, Rubia K, Meindl T, Ettinger U (2013) Methylphenidate effects on neural activity during response inhibition in healthy humans. Cereb Cortex 23:1179-1189

Crunelle CL, van den Brink W, Moggi F, Konstenius M, Franck J, Levin FR, van de Glind G, Demetrovics Z, Coetzee C, Luderer M, Schellekens A, ICASA consensus group, Matthys F, (2018) International Consensus Statement on Screening, Diagnosis and Treatment of Substance Use Disorder Patients with Comorbid Attention Deficit/Hyperactivity Disorder. Eur Addict Res 24:43-51

Demontis D, Walters RK, Martin J, Mattheisen M, Als TD, Agerbo E, Baldursson G, Belliveau R, Bybjerg-Grauholm J, BaekvadHansen M, Cerrato F, Chambert K, Churchhouse C, Dumont A, Eriksson N, Gandal M, Goldstein JI, Grasby KL, Grove J, Gudmundsson OO, Hansen CS, Hauberg ME, Hollegaard MV, Howrigan DP, Huang H, Maller JB, Martin AR, Martin NG, Moran J, Pallesen J, Palmer DS, Pedersen CB, Pedersen MG, Poterba T, Poulsen JB, Ripke S, Robinson EB, Satterstrom FK, Stefansson H, Stevens C, Turley P, Walters GB, Won H, Wright MJ, ADHD Working Group of the Psychiatric Genomic Consortium (PGC), Early Lifecourse \& Genetic Epidemiology (EAGLE) Consortium, Andreassen OA, Asherson P, Burton CL, Boomsma DI, Cormand B, Dalsgaard S, Franke B, Gelernter J, Geschwind D, Hakonarson H, Haavik J, Kranzler HR, Kuntsi J, Langley K, Lesch KP, Middeldorp C, Reif A, Rohde LA, Roussos P, Schachar R, Sklar P, Sonuga-Barke EJS, Sullivan PF, Thapar A, Tung JY, Waldman ID, Medland SE, Stefansson K, Nordentoft M, Hougaard DM, Werge T, Mors O, Mortensen PB, Daly MJ, Faraone SV, Borglum AD, Neale BM (2019) Discovery of the first genome-wide significant risk loci for attention deficit/ hyperactivity disorder. Nat Genet 51: 63-75
Ding YS, Fowler JS, Volkow ND, Logan J, Gatley SJ, Sugano Y (1995) Carbon-11-d-threo-methylphenidate binding to dopamine transporter in baboon brain. J Nucl Med 36:2298-2305

Ding YS, Fowler JS, Volkow ND, Dewey SL, Wang GJ, Logan J, Gatley SJ, Pappas N (1997) Chiral drugs: comparison of the pharmacokinetics of [11C]d-threo and L-threo-methylphenidate in the human and baboon brain. Psychopharmacology 131:71-78

Dinis-Oliveira RJ (2017) Metabolomics of methylphenidate and ethylphenidate: implications in pharmacological and toxicological effects. Eur J Drug Metab Pharmacokinet 42:11-16

Epstein T, Patsopoulos NA, Weiser M (2014) Immediate-release methylphenidate for attention deficit hyperactivity disorder (ADHD) in adults. Cochrane Database Syst Rev: CD005041.

Faltinsen E, Zwi M, Castells X, Gluud C, Simonsen E, Storebø OJ (2019) Updated 2018 NICE guideline on pharmacological treatments for people with ADHD: a critical look. BMJ Evid Based Med 24:99-102

Faraone SV (2018) The pharmacology of amphetamine and methylphenidate: relevance to the neurobiology of attention-deficit/hyperactivity disorder and other psychiatric comorbidities. Neurosci Biobehav Rev 87:255-270

Faraone SV (2020) The impact of attention-deficit/hyperactivity disorder medications on suicidality: implications and mechanisms. Biol Psychiatry 88:436-437

Faraone SV, Biederman J, Mick E (2006) The age-dependent decline of attention deficit hyperactivity disorder: a meta-analysis of followup studies. Psychol Med 36:159-165

Faraone SV, Biederman J, Wilens TE, Adamson J (2007) A naturalistic study of the effects of pharmacotherapy on substance use disorders among ADHD adults. Psychol Med 37:1743-1752

Faraone SV, Asherson P, Banaschewski T, Biederman J, Buitelaar JK, Ramos-Quiroga JA, Rohde LA, Sonuga-Barke EJ, Tannock R, Franke B (2015) Attention-deficit/hyperactivity disorder. Nat Rev Dis Primers 1:15020

Faraone SV, Banaschewski T, Coghill D, Zheng Y, Biederman J, Bellgrove MA, Newcorn JH, Gignac M, Al Saud NM, Manor I, Rohde LA, Yang L, Cortese S, Almagor D, Stein MA, Albatti TH, Aljoudi HF, Alqahtani MMJ, Asherson P, Atwoli L, Bölte S, Buitelaar JK, Crunelle CL, Daley D, Dalsgaard S, Döpfner M, Espinet S, Fitzgerald M, Franke B, Gerlach M, Haavik J, Hartman CA, Hartung CM, Hinshaw SP, Hoekstra PJ, Hollis C, Kollins SH, Sandra Kooij JJ, Kuntsi J, Larsson H, Li T, Liu J, Merzon E, Mattingly G, Mattos P, McCarthy S, Mikami AY, Molina BSG, Nigg JT, Purper-Ouakil D, Omigbodun OO, Polanczyk GV, Pollak Y, Poulton AS, Rajkumar RP, Reding A, Reif A, Rubia K, Rucklidge J, Romanos M, Ramos-Quiroga JA, Schellekens A, Scheres A, Schoeman R, Schweitzer JB, Shah H, Solanto MV, Sonuga-Barke E, Soutullo C, Steinhausen HC, Swanson JM, Thapar A, Tripp G, van de Glind G, Brink WVD, Van der Oord S, Venter A, Vitiello B, Walitza S, Wang Y (2021) The World Federation of ADHD International Consensus Statement: 208 Evidence-based conclusions about the disorder. Neurosci Biobehav Rev. https://doi.org/10.1016/j.neubiorev.2021.01.022

Fayyad J, Sampson NA, Hwang I, Adamowski T, Aguilar-Gaxiola S, Al-Hamzawi A, Andrade LH, Borges G, de Girolamo G, Florescu S, Gureje O, Haro JM, Hu C, Karam EG, Lee S, NavarroMateu F, O'Neill S, Pennell BE, Piazza M, Posada-Villa J, Ten Have M, Torres Y, Xavier M, Zaslavsky AM, Kessler RC, WHO World Mental Health Survey Collaborators (2017) The descriptive epidemiology of DSM-IV Adult ADHD in the World Health Organization World Mental Health Surveys. Atten Defic Hyperact Disord 9: 47-65

Fleckenstein AE, Volz TJ, Hanson GR (2009) Psychostimulant-induced alterations in vesicular monoamine transporter-2 function: 
neurotoxic and therapeutic implications. Neuropharmacology 56(Suppl 1):133-138

Food and Drug Administration (2004) Focalin ${ }^{\mathrm{TM}}$ XR (dexmethylphenidate hydrochloride) extended-release capsules. https://www. accessdata.fda.gov/drugsatfda_docs/label/2005/021802lbl.pdf. Accessed 10 Jan 2021

Food and Drug Administration (2010a) Methylin ${ }^{\mathrm{TM}}$ Oral Solution (methylphenidate $\mathrm{HCl}$ oral solution, $5 \mathrm{mg} / 5 \mathrm{~mL}$; methylphenidate $\mathrm{HCl}$ oral solution, $10 \mathrm{mg} / 5 \mathrm{~mL}$ ). https://www.acces sdata.fda.gov/drugsatfda_docs/label/2010/021419s004lbl.pdf. Accessed 10 Jan 2021

Food and Drug Administration (2010b) Ritalin LA® (methylphenidate hydrochloride) extended-release capsules. https://www.acces sdata.fda.gov/drugsatfda_docs/label/2019/021284s016s029lbl. pdf. Accessed 10 Jan 2021

Food and Drug Administration (2017a) Concerta ${ }^{\circledR}$ (methylphenidate $\mathrm{HCl}$ ) Extended-Release Tablets CII. https://www.accessdata.fda. gov/drugsatfda_docs/label/2017/021121s038lbl.pdf. Accessed 10 Jan 2021

Food and Drug Administration (2017b) Cotempla XR-ODT (methylphenidate extended-release orally disintegrating tablets). https:// www.accessdata.fda.gov/drugsatfda_docs/label/2017/20548 9s000lbl.pdf. Accessed 10 Jan 2021

Food and Drug Administration (2017c) Daytrana ${ }^{\circledR}$ (methylphenidate transdermal system). https://www.accessdata.fda.gov/drugs atfda_docs/label/2017/021514s025lbl.pdf. Accessed 10 Jan 2021

Food and Drug Administration (2017d) Methylin ${ }^{\circledR}$ Chewable Tablets (methylphenidate $\mathrm{HCl}$ chewable tablets) $2.5 \mathrm{mg}, 5 \mathrm{mg}$ and 10 mg. https://www.accessdata.fda.gov/drugsatfda_docs/label/2017/ 021475s010lbl.pdf. Accessed 10 Jan 2021

Food and Drug Administration (2018) Quillivant XR (methylphenidate hydrochloride) for extended-release oral suspension. https:// www.accessdata.fda.gov/drugsatfda_docs/label/2017/20210 0s012lbl.pdf. Accessed 10 Jan 2021

Food and Drug Administration (2019) Adhansia XR (methylphenidate hydrochloride) extended-release capsules, for oral use, CII. https://www.accessdata.fda.gov/drugsatfda_docs/label/2019/ 212038Orig1s000lbl.pdf. Accessed 10 Jan 2021

Franke B, Michelini G, Asherson P, Banaschewski T, Bilbow A, Buitelaar JK, Cormand B, Faraone SV, Ginsberg Y, Haavik J, Kuntsi J, Larsson H, Lesch KP, Ramos-Quiroga JA, Réthelyi JM, Ribases M, Reif A (2018) Live fast, die young? A review on the developmental trajectories of ADHD across the lifespan. Eur Neuropsychopharmacol 28:1059-1088

Fredriksen M, Halmøy A, Faraone SV, Haavik J (2013) Long-term efficacy and safety of treatment with stimulants and atomoxetine in adult ADHD: a review of controlled and naturalistic studies. Eur Neuropsychopharmacol 23:508-527

Frodl T, Skokauskas N (2012) Meta-analysis of structural MRI studies in children and adults with attention deficit hyperactivity disorder indicates treatment effects. Acta Psychiatr Scand 125:114-126

Furini CRG, Behling JAK, Zinn CG, Zanini ML, Assis Brasil E, Pereira LD, Izquierdo I, de Carvalho MJ (2017) Extinction memory is facilitated by methylphenidate and regulated by dopamine and noradrenaline receptors. Behav Brain Res 326:303-306

Gamo NJ, Wang M, Arnsten AF (2010) Methylphenidate and atomoxetine enhance prefrontal function through alpha2-adrenergic and dopamine D1 receptors. J Am Acad Child Adolesc Psychiatry 49:1011-1023

German CL, Baladi MG, McFadden LM, Hanson GR, Fleckenstein AE (2015) Regulation of the dopamine and vesicular monoamine transporters: pharmacological targets and implications for disease. Pharmacol Rev 67:1005-1024

Ginsberg Y, Arngrim T, Philipsen A, Gandhi P, Chen CW, Kumar V, Huss M (2014a) Long-term (1 year) safety and efficacy of methylphenidate modified-release long-acting formulation
(MPH-LA) in adults with attention-deficit hyperactivity disorder: a 26-week, flexible-dose, open-label extension to a 40-week, double-blind, randomised, placebo-controlled core study. CNS Drugs 28:951-962

Ginsberg Y, Beusterien KM, Amos K, Jousselin C, Asherson P (2014b) The unmet needs of all adults with ADHD are not the same: a focus on Europe. Expert Rev Neurother 14:799-812

Guyatt GH, Oxman AD, Kunz R, Atkins D, Brożek J, Vist G, Alderson P, Glasziou P, Falck-Ytter Y, Schünemann HJ (2011) GRADE guidelines: 2. Framing the question and deciding on important outcomes. J Clin Epidemiol 64:395-400

Habel LA, Cooper WO, Sox CM, Chan KA, Fireman BH, Arbogast PG, Cheetham TC, Quinn VP, Dublin S, Boudreau DM, Andrade SE, Pawloski PA, Raebel MA, Smith DH, Achacoso N, Uratsu C, Go AS, Sidney S, Nguyen-Huynh MN, Ray WA, Selby JV (2011) ADHD medications and risk of serious cardiovascular events in young and middle-aged adults. JAMA 306:2673-2683

Haervig KB, Mortensen LH, Hansen AV, Strandberg-Larsen K (2014) Use of ADHD medication during pregnancy from 1999 to 2010: a Danish register-based study. Pharmacoepidemiol Drug Saf 23:526-533

Hart H, Radua J, Nakao T, Mataix-Cols D, Rubia K (2013) Meta-analysis of functional magnetic resonance imaging studies of inhibition and attention in attention-deficit/hyperactivity disorder: exploring task-specific, stimulant medication, and age effects. JAMA Psychiatry 70:185-198

Heal DJ, Pierce DM (2006) Methylphenidate and its isomers: their role in the treatment of attention-deficit hyperactivity disorder using a transdermal delivery system. CNS Drugs 20:713-738

Helfer B, Cooper RE, Bozhilova N, Maltezos S, Kuntsi J, Asherson $P$ (2019) The effects of emotional lability, mind wandering and sleep quality on ADHD symptom severity in adults with ADHD. Eur Psychiatry 55:45-51

Hiemke C, Bergemann N, Clement HW, Conca A, Deckert J, Domschke K, Eckermann G, Egberts K, Gerlach M, Greiner C, Gründer G, Haen E, Havemann-Reinecke U, Hefner G, Helmer R, Janssen G, Jaquenoud E, Laux G, Messer T, Mössner R, Müller MJ, Paulzen M, Pfuhlmann B, Riederer P, Saria A, Schoppek B, Schoretsanitis G, Schwarz M, Gracia MS, Stegmann B, Steimer W, Stingl JC, Uhr M, Ulrich S, Unterecker S, Waschgler R, Zernig G, Zurek G, Baumann P (2018) Consensus Guidelines for Therapeutic Drug Monitoring in Neuropsychopharmacology: Update 2017. Pharmacopsychiatry 51:9-62

Hirsch O, Chavanon M, Riechmann E, Christiansen H (2018) Emotional dysregulation is a primary symptom in adult attention-deficit/hyperactivity disorder (ADHD). J Affect Disord 232:41-47

Hirsch O, Chavanon ML, Christiansen H (2019) Emotional dysregulation subgroups in patients with adult Attention-Deficit/Hyperactivity Disorder (ADHD): a cluster analytic approach. Sci Rep 9:5639

Hodgkins P, Shaw M, Coghill D, Hechtman L (2012) Amfetamine and methylphenidate medications for attention-deficit/hyperactivity disorder: complementary treatment options. Eur Child Adolesc Psychiatry 21:477-492

Hondebrink L, Rietjens SJ, Hunault CC, Pereira RR, Kelleci N, Yasar G, Ghebreslasie A, Lo AFC, De Vries I, Meulenbelt J (2015) Methylphenidate intoxications in children and adults: exposure circumstances and evidence-based dose threshold for pre-hospital triage. Clin Toxicol (phila) 53:168-177

Hoogman M, Bralten J, Hibar DP, Mennes M, Zwiers MP, Schweren LSJ, van Hulzen KJE, Medland SE, Shumskaya E, Jahanshad N, Zeeuw P, Szekely E, Sudre G, Wolfers T, Onnink AMH, Dammers JT, Mostert JC, Vives-Gilabert Y, Kohls G, Oberwelland E, Seitz J, Schulte-Rüther M, Ambrosino S, Doyle AE, Høvik MF, Dramsdahl M, Tamm L, van Erp TGM, Dale A, Schork A, Conzelmann A, Zierhut K, Baur R, McCarthy H, Yoncheva YN, 
Cubillo A, Chantiluke K, Mehta MA, Paloyelis Y, Hohmann S, Baumeister S, Bramati I, Mattos P, Tovar-Moll F, Douglas P, Banaschewski T, Brandeis D, Kuntsi J, Asherson P, Rubia K, Kelly C, Martino AD, Milham MP, Castellanos FX, Frodl T, Zentis M, Lesch KP, Reif A, Pauli P, Jernigan TL, Haavik J, Plessen KJ, Lundervold AJ, Hugdahl K, Seidman LJ, Biederman J, Rommelse N, Heslenfeld DJ, Hartman CA, Hoekstra PJ, Oosterlaan J, Polier GV, Konrad K, Vilarroya O, Ramos-Quiroga JA, Soliva JC, Durston S, Buitelaar JK, Faraone SV, Shaw P, Thompson PM, Franke B (2017) Subcortical brain volume differences in participants with attention deficit hyperactivity disorder in children and adults: a cross-sectional mega-analysis. Lancet Psychiatry 4:310-319

Hoogman M, Muetzel R, Guimaraes JP, Shumskaya E, Mennes M, Zwiers MP, Jahanshad N, Sudre G, Wolfers T, Earl EA, Soliva Vila JC, Vives-Gilabert Y, Khadka S, Novotny SE, Hartman CA, Heslenfeld DJ, Schweren LJS, Ambrosino S, Oranje B, de Zeeuw P, Chaim-Avancini TM, Rosa PGP, Zanetti MV, Malpas CB, Kohls G, von Polier GG, Seitz J, Biederman J, Doyle AE, Dale AM, van Erp TGM, Epstein JN, Jernigan TL, Baur-Streubel R, Ziegler GC, Zierhut KC, Schrantee A, Høvik MF, Lundervold AJ, Kelly C, McCarthy H, Skokauskas N, O'Gorman Tuura RL, Calvo A, Lera-Miguel S, Nicolau R, Chantiluke KC, Christakou A, Vance A, Cercignani M, Gabel MC, Asherson P, Baumeister S, Brandeis D, Hohmann S, Bramati IE, Tovar-Moll F, Fallgatter AJ, Kardatzki B, Schwarz L, Anikin A, Baranov A, Gogberashvili T, Kapilushniy D, Solovieva A, El Marroun H, White T, Karkashadze G, Namazova-Baranova L, Ethofer T, Mattos P, Banaschewski T, Coghill D, Plessen KJ, Kuntsi J, Mehta MA, Paloyelis Y, Harrison NA, Bellgrove MA, Silk TJ, Cubillo AI, Rubia K, Lazaro L, Brem S, Walitza S, Frodl T, Zentis M, Castellanos FX, Yoncheva YN, Haavik J, Reneman L, Conzelmann A, Lesch KP, Pauli P, Reif A, Tamm L, Konrad K, Oberwelland Weiss E, Busatto GF, Louza MR, Durston S, Hoekstra PJ, Oosterlaan J, Stevens MC, Ramos-Quiroga JA, Vilarroya O, Fair DA, Nigg JT, Thompson PM, Buitelaar JK, Faraone SV, Shaw P, Tiemeier H, Bralten J, Franke B (2019) Brain imaging of the cortex in ADHD: a coordinated analysis of large-scale clinical and population-based samples. Am J Psychiatry 176:531-542

Huang HC, Wu LS, Yu SC, Wu BJ, Lua AC, Lee SM, Liu CZ (2018) The Alpha-2A adrenergic receptor gene $-1291 \mathrm{C} / \mathrm{G}$ single nucleotide polymorphism is associated with the efficacy of methylphenidate in treating Taiwanese children and adolescents with attention-deficit hyperactivity disorder. Psychiatry Investig 15:306-312

Huss M, Ginsberg Y, Tvedten T, Arngrim T, Philipsen A, Carter K, Chen CW, Kumar V (2014) Methylphenidate hydrochloride modified-release in adults with attention deficit hyperactivity disorder: a randomized double-blind placebo-controlled trial. Adv Ther 31:44-65

Huss M, Duhan P, Gandhi P, Chen CW, Spannhuth C, Kumar V (2017) Methylphenidate dose optimization for ADHD treatment: review of safety, efficacy, and clinical necessity. Neuropsychiatr Dis Treat 13:1741-1751

Joseph A, Kosmas CE, Patel C, Doll H, Asherson P (2019) Healthrelated quality of life and work productivity of adults with ADHD: a U.K. web-based cross-sectional survey. J Atten Disord 23:1610-1623

Kapur A (2020) Is methylphenidate beneficial and safe in pharmacological cognitive enhancement? CNS Drugs 34:1045-1062

Katzman MA, Bilkey TS, Chokka PR, Fallu A, Klassen LJ (2017) Adult ADHD and comorbid disorders: clinical implications of a dimensional approach. BMC Psychiatry 17:302

Kimko HC, Cross JT, Abernethy DR (1999) Pharmacokinetics and clinical effectiveness of methylphenidate. Clin Pharmacokinet $37: 457-470$
Kis B, Lücke C, Abdel-Hamid M, Heßmann P, Graf E, Berger M, Matthies S, Borel P, Sobanski E, Alm B, Rösler M, Retz W, Jacob C, Colla M, Huss M, Jans T, van Elst LT, Müller HHO, Philipsen A (2020) Safety profile of methylphenidate under long-term treatment in adult ADHD patients - results of the COMPAS Study. Pharmacopsychiatry 53:263-271

Kok FM, Groen Y, Fuermaier ABM, Tucha O (2020) The female side of pharmacotherapy for ADHD - a systematic literature review. PLoS One 15: e0239257.

Kooij JJS (2013) Adult ADHD: Diagnostic Assessment and Treatment, 3rd edn. Springer

Kooij SJ, Bejerot S, Blackwell A, Caci H, Casas-Brugue M, Carpentier PJ, Edvinsson D, Fayyad J, Foeken K, Fitzgerald M, Gaillac V, Ginsberg Y, Henry C, Krause J, Lensing MB, Manor I, Niederhofer H, Nunes-Filipe C, Ohlmeier MD, Oswald P, Pallanti S, Pehlivanidis A, Ramos-Quiroga JA, Rastam M, Ryffel-Rawak D, Stes S, Asherson P (2010) European consensus statement on diagnosis and treatment of adult ADHD: The European Network Adult ADHD. BMC Psychiatry 10:67

Kooij JJS, Bijlenga D, Salerno L, Jaeschke R, Bitter I, Balázs J, Thome J, Dom G, Kasper S, Nunes Filipe C, Stes S, Mohr P, Leppämäki S, Casas Brugué M, Bobes J, McCarthy JM, Richarte V, Kjems Philipsen A, Pehlivanidis A, Niemela A, Styr B, Semerci B, Bolea-Alamanac B, Edvinsson D, Baeyens D, Wynchank D, Sobanski E, Philipsen A, McNicholas F, Caci H, Mihailescu I, Manor I, Dobrescu I, Saito T, Krause J, Fayyad J, Ramos-Quiroga JA, Foeken K, Rad F, Adamou M, Ohlmeier M, Fitzgerald M, Gill M, Lensing M, Motavalli Mukaddes N, Brudkiewicz P, Gustafsson P, Tani P, Oswald P, Carpentier PJ, De Rossi P, Delorme R, Markovska Simoska S, Pallanti S, Young S, Bejerot S, Lehtonen T, Kustow J, Müller-Sedgwick U, Hirvikoski T, Pironti V, Ginsberg Y, Félegyházy Z, GarciaPortilla MP, Asherson P (2019a) Updated European Consensus Statement on diagnosis and treatment of adult ADHD. Eur Psychiatry 56:14-34

Kooij JJS, Francken MH, Bron TI, Wynchank D (2019b) Diagnostic Interview for ADHD in Adults (3rd Edition; DIVA-5). DIVA Foundation, The Hague, The Netherlands

Koren G, Barer Y, Ornoy A (2020) Fetal safety of methylphenidate - a scoping review and meta analysis. Reprod Toxicol 93:230-234

Krinzinger H, Hall CL, Groom MJ, Ansari MT, Banaschewski T, Buitelaar JK, Carucci S, Coghill D, Danckaerts M, Dittmann RW, Falissard B, Garas P, Inglis SK, Kovshoff H, Kochhar P, McCarthy S, Nagy P, Neubert A, Roberts S, Sayal K, SonugaBarke E, Wong ICK, Xia J, Zuddas A, Hollis C, Konrad K, Liddle EB, ADDUCE Consortium (2019) Neurological and psychiatric adverse effects of long-term methylphenidate treatment in ADHD: a map of the current evidence. Neurosci Biobehav Rev 107: $945-968$

Lam AP, Matthies S, Graf E, Colla M, Jacob C, Sobanski E, Alm B, Rösler M, Retz W, Retz-Junginger P, Kis B, Abdel-Hamid M, Müller HHO, Lücke C, Huss M, Jans T, Berger M, Tebartz van Elst L, Philipsen A, Comparison of methylphenidate and psychotherapy in adult ADHD Study (COMPAS) Consortium (2019) Long-term Effects of Multimodal Treatment on Adult Attention-Deficit/Hyperactivity Disorder Symptoms: Follow-up Analysis of the COMPAS Trial. JAMA Netw Open 2: e194980.

Lange KW, Reichl S, Lange KM, Tucha L, Tucha O (2010) The history of attention deficit hyperactivity disorder. Atten Defic Hyperact Disord 2:241-255

Lenzi F, Cortese S, Harris J, Masi G (2018) Pharmacotherapy of emotional dysregulation in adults with ADHD: a systematic review and meta-analysis. Neurosci Biobehav Rev 84:359-367 
Leonard BE, McCartan D, White J, King DJ (2004) Methylphenidate: a review of its neuropharmacological, neuropsychological and adverse clinical effects. Hum Psychopharmacol 19:151-180

Leucht S, Hierl S, Kissling W, Dold M, Davis JM (2012) Putting the efficacy of psychiatric and general medicine medication into perspective: review of meta-analyses. Br J Psychiatry 200:97-106

Li L, Sujan AC, Butwicka A, Chang Z, Cortese S, Quinn P, Viktorin A, Öberg AS, D'Onofrio BM, Larsson H (2020) Associations of prescribed ADHD medication in pregnancy with pregnancyrelated and offspring outcomes: a systematic review. CNS Drugs 34:731-747

Lichtenstein P, Halldner L, Zetterqvist J, Sjolander A, Serlachius E, Fazel S, Langstrom N, Larsson H (2012) Medication for attention deficit-hyperactivity disorder and criminality. N Engl J Med 367:2006-2014

Liddle EB, Hollis C, Batty MJ, Groom MJ, Totman JJ, Liotti M, Scerif G, Liddle PF (2011) Task-related default mode network modulation and inhibitory control in ADHD: effects of motivation and methylphenidate. J Child Psychol Psychiatry 52:761-771

Linssen AM, Sambeth A, Vuurman EF, Riedel WJ (2014) Cognitive effects of methylphenidate in healthy volunteers: a review of single dose studies. Int J Neuropsychopharmacol 17:961-977

Maldonado R (2013) Comparison of the pharmacokinetics and clinical efficacy of new extended-release formulations of methylphenidate. Expert Opin Drug Metab Toxicol 9:1001-1014

Markowitz JS, Patrick KS (2008) Differential pharmacokinetics and pharmacodynamics of methylphenidate enantiomers: does chirality matter? J Clin Psychopharmacol 28:S54-61

Markowitz JS, Logan BK, Diamond F, Patrick KS (1999) Detection of the novel metabolite ethylphenidate after methylphenidate overdose with alcohol coingestion. J Clin Psychopharmacol 19:362-366

Markowitz JS, DeVane CL, Boulton DW, Nahas Z, Risch SC, Diamond F, Patrick KS (2000) Ethylphenidate formation in human subjects after the administration of a single dose of methylphenidate and ethanol. Drug Metab Dispos 28:620-624

Markowitz JS, Straughn AB, Patrick KS (2003a) Advances in the pharmacotherapy of attention-deficit-hyperactivity disorder: focus on methylphenidate formulations. Pharmacotherapy 23:1281-1299

Markowitz JS, Straughn AB, Patrick KS, DeVane CL, Pestreich L, Lee J, Wang Y, Muniz R (2003b) Pharmacokinetics of methylphenidate after oral administration of two modified-release formulations in healthy adults. Clin Pharmacokinet 42:393-401

Markowitz JS, DeVane CL, Pestreich LK, Patrick KS, Muniz R (2006) A comprehensive in vitro screening of d-, 1-, and dl-threo-methylphenidate: an exploratory study. J Child Adolesc Psychopharmacol 16:687-698

Markowitz JS, DeVane CL, Ramamoorthy S, Zhu HJ (2009) The psychostimulant d-threo-(R, R)-methylphenidate binds as an agonist to the 5HT(1A) receptor. Pharmazie 64:123-125

Martinez-Raga J, Knecht C, Szerman N, Martinez MI (2013) Risk of serious cardiovascular problems with medications for attentiondeficit hyperactivity disorder. CNS Drugs 27:15-30

Masuch TV, Bea M, Alm B, Deibler P, Sobanski E (2019) Internalized stigma, anticipated discrimination and perceived public stigma in adults with ADHD. Atten Defic Hyperact Disord 11:211-220

Mattingly GW, Wilson J, Ugarte L, Glaser P (2020) Individualization of attention-deficit/hyperactivity disorder treatment: pharmacotherapy considerations by age and co-occurring conditions. CNS Spectr: 1-20.

McAllister-Williams RH, Baldwin DS, Cantwell R, Easter A, Gilvarry E, Glover V, Green L, Gregoire A, Howard LM, Jones I, Khalifeh $\mathrm{H}$, Lingford-Hughes A, McDonald E, Micali N, Pariante CM, Peters L, Roberts A, Smith NC, Taylor D, Wieck A, Yates LM, Young AH, endorsed by the British Association for Psychopharmacology, (2017) British Association for Psychopharmacology consensus guidance on the use of psychotropic medication preconception, in pregnancy and postpartum 2017. J Psychopharmacol 31:519-552

McNeil Pediatrics (2007) Product information: Concerta extended release oral tablets, methylphenidate $\mathrm{HCl}$ extended-release oral tablets

Michelini G, Jurgiel J, Bakolis I, Cheung CHM, Asherson P, Loo SK, Kuntsi J, Mohammad-Rezazadeh I (2019) Atypical functional connectivity in adolescents and adults with persistent and remitted ADHD during a cognitive control task. Transl Psychiatry 9:137

Michielsen M, Kleef D, Bijlenga D, Zwennes C, Dijkhuizen K, Smulders J, Hazewinkel A, Beekman ATF, Kooij JJS (2020) Response and side effects using stimulant medication in older adults with ADHD: an observational archive study. J Atten Disord: 1087054720925884 .

Modi NB, Lindemulder B, Gupta SK (2000a) Single- and multipledose pharmacokinetics of an oral once-a-day osmotic controlledrelease OROS (methylphenidate $\mathrm{HCl}$ ) formulation. J Clin Pharmacol 40:379-388

Modi NB, Wang B, Hu WT, Gupta SK (2000b) Effect of food on the pharmacokinetics of osmotic controlled-release methylphenidate $\mathrm{HCl}$ in healthy subjects. Biopharm Drug Dispos 21:23-31

Modi NB, Wang B, Noveck RJ, Gupta SK (2000c) Dose-proportional and stereospecific pharmacokinetics of methylphenidate delivered using an osmotic, controlled-release oral delivery system. J Clin Pharmacol 40:1141-1149

Moeller SJ, Honorio J, Tomasi D, Parvaz MA, Woicik PA, Volkow ND, Goldstein RZ (2014) Methylphenidate enhances executive function and optimizes prefrontal function in both health and cocaine addiction. Cereb Cortex 24:643-653

Moran LV, Ongur D, Hsu J, Castro VM, Perlis RH, Schneeweiss S (2019) Psychosis with methylphenidate or amphetamine in patients with ADHD. N Engl J Med 380:1128-1138

Moukhtarian TR, Mintah RS, Moran P, Asherson P (2018) Emotion dysregulation in attention-deficit/hyperactivity disorder and borderline personality disorder. Borderline Personal Disord Emot Dysregul 5:9

Mueller AK, Fuermaier AB, Koerts J, Tucha L (2012) Stigma in attention deficit hyperactivity disorder. Atten Defic Hyperact Disord 4:101-114

Mueller S, Costa A, Keeser D, Pogarell O, Berman A, Coates U, Reiser MF, Riedel M, Moller HJ, Ettinger U, Meindl T (2014) The effects of methylphenidate on whole brain intrinsic functional connectivity. Hum Brain Mapp 35:5379-5388

Murad MH, Montori VM, Ioannidis JP, Jaeschke R, Devereaux PJ, Prasad K, Neumann I, Carrasco-Labra A, Agoritsas T, Hatala R, Meade MO, Wyer P, Cook DJ, Guyatt G (2014) How to read a systematic review and meta-analysis and apply the results to patient care: users' guides to the medical literature. JAMA 312:171-179

Murad MH, Asi N, Alsawas M, Alahdab F (2016) New evidence pyramid. Evid Based Med 21:125-127

National Institute for Health and Care Excellence (2018) NICE guideline. Attention deficit hyperactivity disorder: diagnosis and management. National Institute for Health and Care Excellence (UK)

Ornoy A (2018) Pharmacological treatment of attention deficit hyperactivity disorder during pregnancy and lactation. Pharm Res $35: 46$

Osland ST, Steeves TD, Pringsheim T (2018) Pharmacological treatment for attention deficit hyperactivity disorder (ADHD) in children with comorbid tic disorders. Cochrane Database Syst Rev 6: CD007990.

Patrick KS, González MA, Straughn AB, Markowitz JS (2005) New methylphenidate formulations for the treatment of attention-deficit/hyperactivity disorder. Expert Opin Drug Deliv 2:121-143 
Patrick KS, Straughn AB, Minhinnett RR, Yeatts SD, Herrin AE, DeVane CL, Malcolm R, Janis GC, Markowitz JS (2007) Influence of ethanol and gender on methylphenidate pharmacokinetics and pharmacodynamics. Clin Pharmacol Ther 81:346-353

Patrick KS, Radke JL, Raymond JR, Koller L, Nguyen LV, Rodriguez W, Straughn AB (2019) Drug regimen individualization for attention-deficit/hyperactivity disorder: guidance for methylphenidate and dexmethylphenidate formulations. Pharmacotherapy 39:677-688

Pauly V, Frauger E, Lepelley M, Mallaret M, Boucherie Q, Micallef J (2018) Patterns and profiles of methylphenidate use both in children and adults. Br J Clin Pharmacol 84:1215-1227

Philipsen A, Jans T, Graf E, Matthies S, Borel P, Colla M, Gentschow L, Langner D, Jacob C, Groß-Lesch S, Sobanski E, Alm B, Schumacher-Stien M, Roesler M, Retz W, Retz-Junginger P, Kis B, Abdel-Hamid M, Heinrich V, Huss M, Kornmann C, Bürger A, Perlov E, Ihorst G, Schlander M, Berger M, Tebartz van Elst L (2015) Effects of group psychotherapy, individual counseling, methylphenidate, and placebo in the treatment of adult attentiondeficit/hyperactivity disorder: a randomized clinical trial. JAMA Psychiatry 72:1199-1210

Pliszka SR (2019) Is there long-term benefit from stimulant treatment for ADHD? Am J Psychiatry 176:685-686

Polanczyk GV, Salum GA, Sugaya LS, Caye A, Rohde LA (2015) Annual Research Review: A meta-analysis of the worldwide prevalence of mental disorders in children and adolescents. J Child Psychol Psychiatry 56:345-365

Posner J, Polanczyk GV, Sonuga-Barke E (2020) Attention-deficit hyperactivity disorder. Lancet 395:450-462

Pottegård A, Bjerregaard BK, Glintborg D, Kortegaard LS, Hallas J, Moreno SI (2013) The use of medication against attention deficit/hyperactivity disorder in Denmark: a drug use study from a patient perspective. Eur J Clin Pharmacol 69:589-598

Poulton AS, Armstrong B, Nanan RK (2018) Perinatal outcomes of women diagnosed with attention-deficit/hyperactivity disorder: an Australian population-based cohort study. CNS Drugs 32:377-386

Preuss CV, Kalava A, King KC (2020) Prescription of controlled substances: benefits and risks StatPearls, Treasure Island (FL)

Quinn PD, Chang Z, Hur K, Gibbons RD, Lahey BB, Rickert ME, Sjölander A, Lichtenstein P, Larsson H, D'Onofrio BM (2017) ADHD medication and substance-related problems. Am J Psychiatry 174:877-885

Raman SR, Man KKC, Bahmanyar S, Berard A, Bilder S, Boukhris T, Bushnell G, Crystal S, Furu K, KaoYang YH, Karlstad O, Kieler H, Kubota K, Lai EC, Martikainen JE, Maura G, Moore N, Montero D, Nakamura H, Neumann A, Pate V, Pottegard A, Pratt NL, Roughead EE, Macias Saint-Gerons D, Sturmer T, Su CC, Zoega H, Sturkenbroom M, Chan EW, Coghill D, Ip P, Wong ICK (2018) Trends in attention-deficit hyperactivity disorder medication use: a retrospective observational study using population-based databases. Lancet Psychiatry 5:824-835

Ramos L, Bakhtiar R, Majumdar T, Hayes M, Tse F (1999) Liquid chromatography/atmospheric pressure chemical ionization tandem mass spectrometry enantiomeric separation of dl-threomethylphenidate, (Ritalin) using a macrocyclic antibiotic as the chiral selector. Rapid Commun Mass Spectrom 13:2054-2062

Reed GM, First MB, Kogan CS, Hyman SE, Gureje O, Gaebel W, Maj M, Stein DJ, Maercker A, Tyrer P, Claudino A, Garralda E, Salvador-Carulla L, Ray R, Saunders JB, Dua T, Poznyak V, Medina-Mora ME, Pike KM, Ayuso-Mateos JL, Kanba S, Keeley JW, Khoury B, Krasnov VN, Kulygina M, Lovell AM, de Jesus MJ, Maruta T, Matsumoto C, Rebello TJ, Roberts MC, Robles R, Sharan P, Zhao M, Jablensky A, Udomratn P, RahimiMovaghar A, Rydelius PA, Bährer-Kohler S, Watts AD, Saxena $S$ (2019) Innovations and changes in the ICD-11 classification of mental, behavioural and neurodevelopmental disorders. World Psychiatry 18:3-19

Retz W, Retz-Junginger P (2014) Prediction of methylphenidate treatment outcome in adults with attention-deficit/hyperactivity disorder (ADHD). Eur Arch Psychiatry Clin Neurosci 264(Suppl 1):S35-43

Riddle EL, Hanson GR, Fleckenstein AE (2007) Therapeutic doses of amphetamine and methylphenidate selectively redistribute the vesicular monoamine transporter-2. Eur J Pharmacol 571:25-28

Rietjens SJ, Hondebrink L, Jorna T, de Vries I (2017) Methylphenidate poisoning: relatively mild symptoms even after high-dose exposure. Clin Toxicol (phila) 55:941-942

Rochdi M, González MA, Dirksen SJ (2004) Dose-proportional pharmacokinetics of a methylphenidate extended-release capsule. Int J Clin Pharmacol Ther 42:285-292

Roselló B, Berenguer C, Baixauli I, Mira A, Martinez-Raga J, Miranda A (2020) Empirical examination of executive functioning, ADHD associated behaviors, and functional impairments in adults with persistent ADHD, remittent ADHD, and without ADHD. BMC Psychiatry 20:134

Sandoval V, Riddle EL, Hanson GR, Fleckenstein AE (2002) Methylphenidate redistributes vesicular monoamine transporter-2: role of dopamine receptors. J Neurosci 22:8705-8710

Scharman EJ, Erdman AR, Cobaugh DJ, Olson KR, Woolf AD, Caravati EM, Chyka PA, Booze LL, Manoguerra AS, Nelson LS, Christianson G, Troutman WG, Association A, of Poison Control Centers, (2007) Methylphenidate poisoning: an evidencebased consensus guideline for out-of-hospital management. Clin Toxicol (phila) 45:737-752

Schelleman H, Bilker WB, Kimmel SE, Daniel GW, Newcomb C, Guevara JP, Cziraky MJ, Strom BL, Hennessy S (2012) Methylphenidate and risk of serious cardiovascular events in adults. Am J Psychiatry 169:178-185

Schlösser RG, Nenadic I, Wagner G, Zysset S, Koch K, Sauer H (2009) Dopaminergic modulation of brain systems subserving decision making under uncertainty: a study with fMRI and methylphenidate challenge. Synapse 63:429-442

Schoretsanitis G, de Leon J, Eap CB, Kane JM, Paulzen M (2019) Clinically significant drug-drug interactions with agents for attention-deficit/hyperactivity disorder. CNS Drugs 33:1201-1222

Schweitzer JB, Lee DO, Hanford RB, Zink CF, Ely TD, Tagamets MA, Hoffman JM, Grafton ST, Kilts CD (2004) Effect of methylphenidate on executive functioning in adults with attention-deficit/ hyperactivity disorder: normalization of behavior but not related brain activity. Biol Psychiatry 56:597-606

Shaw P, Stringaris A, Nigg J, Leibenluft E (2014) Emotion dysregulation in attention deficit hyperactivity disorder. Am J Psychiatry 171:276-293

Shekelle PG (2018) Clinical Practice Guidelines: What's Next? JAMA 320:757-758

Shin JY, Roughead EE, Park BJ, Pratt NL (2016) Cardiovascular safety of methylphenidate among children and young people with attention-deficit/hyperactivity disorder (ADHD): nationwide self controlled case series study. BMJ 353: i2550.

Skoglund C, Brandt L, D’Onofrio B, Larsson H, Franck J (2017) Methylphenidate doses in attention deficit/hyperactivity disorder and comorbid substance use disorders. Eur Neuropsychopharmacol 27:1144-1152

Spencer TJ, Brown A, Seidman LJ, Valera EM, Makris N, Lomedico A, Faraone SV, Biederman J (2013) Effect of psychostimulants on brain structure and function in ADHD: a qualitative literature review of magnetic resonance imaging-based neuroimaging studies. J Clin Psychiatry 74:902-917

Spiller HA, Hays HL, Aleguas A Jr (2013) Overdose of drugs for attention-deficit hyperactivity disorder: clinical presentation, 
mechanisms of toxicity, and management. CNS Drugs 27:531-543

Srinivas NR, Hubbard JW, McKay G, Hawes EM, Midha KK (1991) In vitro hydrolysis of RR, SS-threo-methylphenidate by blood esterases-differential and enantioselective interspecies variability. Chirality 3:99-103

Stein MA, Weiss M, Hlavaty L (2012) ADHD treatments, sleep, and sleep problems: complex associations. Neurotherapeutics 9:509-517

Steinbuchel P, Greenhill L (2020) Stimulants: definition, pharmacology, indications, side effects, and treatment strategies. In: Riederer P, Laux G, Nagatsu T, Le W, Riederer C (eds) NeuroPsychopharmacotherapy. Springer, Cham.

Stevens T, Sangkuhl K, Brown JT, Altman RB, Klein TE (2019) PharmGKB summary: methylphenidate pathway, pharmacokinetics/pharmacodynamics. Pharmacogenet Genomics 29:136-154

Sudre G, Mangalmurti A, Shaw P (2018) Growing out of attention deficit hyperactivity disorder: insights from the 'remitted' brain. Neurosci Biobehav Rev 94:198-209

Swanson J, Gupta S, Guinta D, Flynn D, Agler D, Lerner M, Williams L, Shoulson I, Wigal S (1999) Acute tolerance to methylphenidate in the treatment of attention deficit hyperactivity disorder in children. Clin Pharmacol Ther 66:295-305

Swanson J, Gupta S, Lam A, Shoulson I, Lerner M, Modi N, Lindemulder E, Wigal S (2003) Development of a new once-a-day formulation of methylphenidate for the treatment of attentiondeficit/hyperactivity disorder: proof-of-concept and proof-ofproduct studies. Arch Gen Psychiatry 60:204-211

Tamminga HGH, Reneman L, Schrantee A, Bottelier MA, Bouziane C, Geurts HM, Groenman AP (2021) Do effects of methylphenidate on cognitive performance last beyond treatment? A randomized placebo-controlled trial in boys and men with ADHD. Eur Neuropsychopharmacol 46:1-13

Tomasi D, Volkow ND, Wang GJ, Wang R, Telang F, Caparelli EC, Wong C, Jayne M, Fowler JS (2011) Methylphenidate enhances brain activation and deactivation responses to visual attention and working memory tasks in healthy controls. Neuroimage 54:3101-3110

U.S. National Library of Medicine (2020). Methylphenidate. LactMed - a Toxnet database US National Library of Medicine: https:// www.ncbi.nlm.nih.gov/books/NBK501310/

Vatansever D, Bozhilova NS, Asherson P, Smallwood J (2019) The devil is in the detail: exploring the intrinsic neural mechanisms that link attention-deficit/hyperactivity disorder symptomatology to ongoing cognition. Psychol Med 49:1185-1194

Volkow ND, Swanson JM (2003) Variables that affect the clinical use and abuse of methylphenidate in the treatment of ADHD. Am J Psychiatry 160:1909-1918

Volkow ND, Swanson JM (2013) Clinical practice: adult attention deficit-hyperactivity disorder. N Engl J Med 369:1935-1944

Volkow ND, Ding YS, Fowler JS, Wang GJ, Logan J, Gatley JS, Dewey S, Ashby C, Liebermann J, Hitzemann R, Wolf AP (1995) Is methylphenidate like cocaine? Studies on their pharmacokinetics and distribution in the human brain. Arch Gen Psychiatry 52:456-463

Wargin W, Patrick K, Kilts C, Gualtieri CT, Ellington K, Mueller RA, Kraemer G, Breese GR (1983) Pharmacokinetics of methylphenidate in man, rat and monkey. J Pharmacol Exp Ther 226:382-386

Wenthur CJ (2016) Classics in chemical neuroscience: methylphenidate. ACS Chem Neurosci 7:1030-1040

Westbrook A, van den Bosch R, Määttä JI, Hofmans L, Papadopetraki D, Cools R, Frank MJ (2020) Dopamine promotes cognitive effort by biasing the benefits versus costs of cognitive work. Science 367:1362-1366

Westover AN, Halm EA (2012) Do prescription stimulants increase the risk of adverse cardiovascular events?: a systematic review. BMC Cardiovase Disord 12:41

Williard RL, Middaugh LD, Zhu HJ, Patrick KS (2007) Methylphenidate and its ethanol transesterification metabolite ethylphenidate: brain disposition, monoamine transporters and motor activity. Behav Pharmacol 18:39-51

Wolraich ML, Doffing MA (2004) Pharmacokinetic considerations in the treatment of attention-deficit hyperactivity disorder with methylphenidate. CNS Drugs 18:243-250

Wong ICK, Banaschewski T, Buitelaar J, Cortese S, Döpfner M, Simonoff E, Coghill D, European ADHD Guidelines Group (2019) Emerging challenges in pharmacotherapy research on attention-deficit hyperactivity disorder-outcome measures beyond symptom control and clinical trials. Lancet Psychiatry 6: $528-537$

Wynchank D, Bijlenga D, Beekman AT, Kooij JJS, Penninx BW (2017) Adult attention-deficit/hyperactivity disorder (ADHD) and insomnia: an update of the literature. Curr Psychiatry Rep 19:98

Young S, Adamo N, Ásgeirsdóttir BB, Branney P, Beckett M, Colley W, Cubbin S, Deeley Q, Farrag E, Gudjonsson G, Hill P, Hollingdale J, Kilic O, Lloyd T, Mason P, Paliokosta E, Perecherla S, Sedgwick J, Skirrow C, Tierney K, van Rensburg K, Woodhouse E (2020) Females with ADHD: an expert consensus statement taking a lifespan approach providing guidance for the identification and treatment of attention-deficit/ hyperactivity disorder in girls and women. BMC Psychiatry 20:404

Zhang-James Y, Helminen EC, Liu J, ENIGMA-ADHD Working Group, Franke B, Hoogman M, Faraone SV (2021) Evidence for similar structural brain anomalies in youth and adult attentiondeficit/hyperactivity disorder: a machine learning analysis. Transl Psychiatry 11: 82

Zhu HJ, Appel DI, Peterson YK, Wang Z, Markowitz JS (2010) Identification of selected therapeutic agents as inhibitors of carboxylesterase 1: potential sources of metabolic drug interactions. Toxicology 270:59-65

Zhu HJ, Patrick KS, Straughn AB, Reeves OT 3rd, Bernstein H, Shi J, Johnson HJ, Knight JM, Smith AT, Malcolm RJ, Markowitz JS (2017) Ethanol interactions with dexmethylphenidate and dl-methylphenidate spheroidal oral drug absorption systems in healthy volunteers. J Clin Psychopharmacol 37:419-428

Publisher's Note Springer Nature remains neutral with regard to jurisdictional claims in published maps and institutional affiliations. 